Research Article

\title{
Performance of a Three-Substep Time Integration Method on Structural Nonlinear Seismic Analysis
}

\author{
Jinyue Zhang $\mathbb{D}^{D}$, Lei Shi ${ }^{(D)}$, Tianhao Liu $(\mathbb{D}$, De Zhou $(\mathbb{D}$, and Weibin Wen \\ Central South University, Changsha 410083, China \\ Correspondence should be addressed to De Zhou; 210026@csu.edu.cn
}

Received 6 August 2021; Revised 13 November 2021; Accepted 6 December 2021; Published 21 December 2021

Academic Editor: Breno Jacob

Copyright ( 2021 Jinyue Zhang et al. This is an open access article distributed under the Creative Commons Attribution License, which permits unrestricted use, distribution, and reproduction in any medium, provided the original work is properly cited.

In this work, a study of a three substeps' implicit time integration method called the Wen method for nonlinear finite element analysis is conducted. The calculation procedure of the Wen method for nonlinear analysis is proposed. The basic algorithmic property analysis shows that the Wen method has good performance on numerical dissipation, amplitude decay, and period elongation. Three nonlinear dynamic problems are analyzed by the Wen method and other competitive methods. The result comparison indicates that the Wen method is feasible and efficient in the calculation of nonlinear dynamic problems. Theoretical analysis and numerical simulation illustrate that the Wen method has desirable solution accuracy and can be a good candidate for nonlinear dynamic problems.

\section{Introduction}

In last several decades, time dependent hyperbolic equations coupled with their calculation methods are widely used in various field. Generally, it is difficult to obtain analytical responses of these equations. Time-frequency method and time integration method are often used to deal with dynamic problems. For instance, the time-frequency method is an important technology in dynamic response analysis, especially for seismic data processing and interpolation [1]. Timefrequency analysis also plays a very important role in many areas such model updating, vibration control, dynamic optimization, etc. [2]. The time integration method has been employed extensively in linear and nonlinear dynamic problems. In general, time integration methods can be categorized into two major categories: explicit methods [3-5] and implicit methods $[3,6,7]$. Almost all implicit methods are unconditionally stable, and thus a large time step can be adopted. By contrast, most of explicit methods need to adopt a small time step to ensure stability. However, in terms of time cost in one time step, explicit methods have advantage over implicit methods, because the implicit methods spend more computation time for the calculation of stiffness matrix inversion and iteration than explicit methods.
For nonlinear dynamics, both explicit and implicit methods are used to solve different types of problems. Explicit methods are widely used to solve high-frequency transient problems such as impact problems. However, for structural dynamics problems where the dynamic response is mainly composed of low frequency modes, implicit methods are more suitable [8]. For implicit methods, a series of single-step methods such as Newmark method [9], HHT- $\alpha$ method [10], and Generalized- $\alpha$ method [11] are firstly proposed. The trapezoidal rule is extensively employed in these methods, because it performs well in the dynamic analysis of linear systems [12]. However, for nonlinear problems, it is necessary to realize a dynamic balance at each time step in the calculation of matrix iteration [13]. But for trapezoidal rule, it become quite unstable when large deformation occurs in the dynamic analysis of structural system, because it cannot satisfy the conservation of energy and moment of inertia. Actually, Kuhl and Crisfield provide energy-conserving and decaying algorithms for predicting the performance of time integration method in nonlinear analysis [14]. The numerical dissipation of time integration method for filtering or suppression of the spurious highfrequency mode is still very important for nonlinear analysis [15]. However, it is difficult for single-step time integration method to achieve desirable numerical dissipation. 
In order to overcome the shortcomings of single-step methods, Bathe and Baig proposed a composite time integration method [16] (called the Bathe method), which employs trapezoidal rule in the first substep and employs three-point backward Euler formula in the second substep. Theoretical analysis and numerical calculation show that the Bathe method performs well in nonlinear problems [17] and has excellent numerical dissipation property [18]. Following the Bathe method, a lot of composite methods [19-24] have been proposed by adopting different combinations of trapezoidal rule and other formulas. Among these methods, the Wen method [21] has excellent numerical dissipative properties and achieves high accuracy in linear analysis. The performance of the Wen method on nonlinear analysis deserves to be expected.

In this paper, the performance of the Wen method on nonlinear analysis will be studied through theoretical analysis and numerical simulation. In Section 2, the calculation procedure of the Wen method for nonlinear system is given. In Section 3, the basic algorithmic properties of the Wen method and other competitive methods are analyzed. In Section 4, numerical simulations of two well-known nonlinear dynamic examples and two nonlinear seismic examples are conducted by using the Wen method and other competitive methods. Finally, some concluding remarks are summarized in Section 5.

\section{The Wen Method for Nonlinear Calculation}

The governing equation of motion for nonlinear structural system discretized by the finite element method can be represented by

$$
M X+F(X, \dot{X}, t)=R(t)
$$

where $M$ is the mass matrix, $F$ is the vector of internal forces, and $R$ is the vector of external forces. $X, \dot{X}$, and $X$ represent the displacement, velocity, and acceleration vectors, respectively. The initial conditions are given by

$$
\begin{aligned}
& X_{0}=X(0), \\
& \dot{X}_{0}=\dot{X}(0), \\
& X_{0}=M^{-1}\left(R(0)-F\left(X_{0}, \dot{X}_{0}, 0\right)\right),
\end{aligned}
$$

where $X_{0}$ and $\dot{X}_{0}$ are, respectively, initial displacement and velocity vectors required to be given before solving the equation. $X_{0}$ is the initial acceleration.

According to the calculation procedure of the Wen method for linear system [21], the time steps corresponding to the three substeps are $p \Delta t,(1-p) \Delta t$, and $\Delta t$, respectively. The parameter $p$ satisfies the condition $0<p<0.406$ to ensure the unconditional stability of the method. The first step of the method uses the trapezoidal rule, the second step adopts the three-point Euler backward formula, and the third step employs the Houbolt formula. The formulas of the first substep are

$$
\begin{gathered}
\dot{X}_{t+p \Delta t}=\dot{X}_{t}+\frac{1}{2} p \Delta t\left(X_{t}+X_{t+p \Delta t}\right), \\
X_{t+p \Delta t}=X_{t}+\frac{1}{2} p \Delta t\left(\dot{X}_{t}+\dot{X}_{t+p \Delta t}\right), \\
M X_{t+p \Delta t}+F_{t+p \Delta t}(X, \dot{X}, t)=R_{t+p \Delta t},
\end{gathered}
$$

where the subscript ' $t+p \Delta t$ ' defines the value at time $t+p \Delta t$.

The formulas of the second substep are

$$
\begin{aligned}
& \dot{X}_{t+(1-p) \Delta t}=m_{1} X_{t}+m_{2} X_{t+p \Delta t}+m_{3} X_{t+(1-p) \Delta t}, \\
& X_{t+(1-p) \Delta t}=m_{1} \dot{X}_{t}+m_{2} \dot{X}_{t+p \Delta t}+m_{3} \dot{X}_{t+(1-p) \Delta t}, \\
& M X_{t+(1-p) \Delta t}+F_{t+(1-p) \Delta t}(X, \dot{X}, t)=R_{t+(1-p) \Delta t},
\end{aligned}
$$

where $m_{1}=2 p-1 / p(p-1) \Delta t, \quad m_{2}=1-p / p(2 p-1) \Delta t$, $m_{3}=2-3 p /(p-1)(2 p-1) \Delta t$.

The formulas of the third substep are

$$
\begin{aligned}
& \dot{X}_{t+\Delta t}=n_{1} X_{t}+n_{2} X_{t+p \Delta t}+n_{3} X_{t+(1-p) \Delta t}+n_{4} X_{t+\Delta t}, \\
& X_{t+\Delta t}=n_{1} \dot{X}_{t}+n_{2} \dot{X}_{t+p \Delta t}+n_{3} \dot{X}_{t+(1-p) \Delta t}+n_{4} \dot{X}_{t+\Delta t}, \\
& M X_{t+\Delta t}+F_{t+\Delta t}(X, \dot{X}, t)=R_{t+\Delta t},
\end{aligned}
$$

where $\quad n_{1}=-1 / \Delta t, \quad n_{2}=1 /(p-1)(2 p-1) \Delta t, \quad n_{3}=1 / p$ $(2 p-1) \Delta t, n_{4}=p^{2}-p-1 / p(p-1) \Delta t$.

In following analysis, the detailed calculation procedure for nonlinear dynamics is deduced. Substituting equations (3) and (4) into equation (5) leads to a residual function in terms of unknown displacement vector $X_{t+p \Delta t}$, which is solved by Newton-Raphson iteration method. After simplification, we obtain $(j=1,2,3, \cdots)$

$$
\begin{aligned}
\frac{4}{(p \Delta t)^{2}} M \Delta X_{t+p \Delta t}^{(j)}= & R_{t+p \Delta t}-F\left(X_{t+p \Delta t}^{(j-1)}, \dot{X}_{t+p \Delta t}^{(j-1)}, t\right) \\
& -M\left(\frac{4}{(p \Delta t)^{2}}\left(X_{t+p \Delta t}^{(j-1)}-X_{t}\right)-\frac{4}{p \Delta t} \dot{X}_{t}-X_{t}\right),
\end{aligned}
$$

where $\Delta X_{t+p \Delta t}^{(j)}=X_{t+p \Delta t}^{(j)}-X_{t+p \Delta t}^{(j-1)}$. Once the displacement vector $X_{t+p \Delta t}$ (i.e., $X_{t+p \Delta t}^{(j)}$ ) is obtained, the velocity and acceleration vectors can be solved with equations (3) and (4).

Likewise, for the second substep, we obtain

$$
\begin{aligned}
m_{3}^{2} M \Delta X_{t+(1-p) \Delta t}^{(j)}= & R_{t+(1-p) \Delta t}-F\left(X_{t+(1-p) \Delta t}^{(j-1)}, \dot{X}_{t+(1-p) \Delta t}^{(j-1)}, t\right) \\
& -M\left(m_{3}^{2} X_{t+(1-p) \Delta t}^{(j-1)}+m_{3} m_{1} X_{t}+m_{1} \dot{X}_{t}\right. \\
& \left.+m_{3} m_{2} X_{t+p \Delta t}+m_{2} \dot{X}_{t+p \Delta t}\right),
\end{aligned}
$$

where $\Delta X_{t+(1-p) \Delta t}^{(j)}=X_{t+(1-p) \Delta t}^{(j)}-X_{t+(1-p) \Delta t}^{(j-1)}$. After $X_{t+(1-p) \Delta t}$ is obtained, $\dot{X}_{t+(1-p) \Delta t}$ and $X_{t+(1-p) \Delta t}$ can be solved with equations (6) and (7). 
As for the third substep, we obtain

$$
n_{4}^{2} M \Delta X_{t+\Delta t}^{(j)}=R_{t+\Delta t}-F\left(X_{t+\Delta t}^{(j-1)}, \dot{X}_{t+\Delta t}^{(j-1)}, t\right)-M\left(\begin{array}{c}
n_{4}^{2} X_{t+\Delta t}^{(j-1)}+n_{4} n_{1} X_{t}+n_{1} \dot{X}_{t}+n_{4} n_{2} X_{t+p \Delta t} \\
+n_{2} \dot{X}_{t+p \Delta t}+n_{4} n_{3} X_{t+(1-p) \Delta t}+n_{3} \dot{X}_{t+(1-p) \Delta t}
\end{array}\right)
$$

where $\Delta X_{t+\Delta t}^{(j)}=X_{t+\Delta t}^{(j)}-X_{t+\Delta t}^{(j-1)}$.

The minimal iteration number $j$ for each substep is determined by the criterion

$$
\sqrt{\frac{\Delta X_{t+r \Delta t}^{(j)} \Delta \Delta X_{t+r \Delta t}^{(j)}}{X_{t+r \Delta t}^{(j)} \Delta X_{t+r \Delta t}^{(j)}}} \leq \varepsilon, r=p, 1-p, 1,
$$

where the tolerance is $\varepsilon=10^{-10}$.

This method is a single parameter method, and all algorithmic properties are related to the algorithm parameter p. In linear analysis, a parameter case of the Wen method is suggested for general linear dynamic problems to obtain desirable algorithmic properties including calculation accuracy, numerical dissipation, etc. $[7,21]$. In structural linear seismic response analysis, the suggested parameter case also has been proved to have higher solution accuracy than other parameter cases [25]. In Section 4, the influence of algorithmic parameters on solution accuracy of nonlinear problems will be analyzed through numerical examples.

\section{Basic Properties of the Wen Method}

In this section, spectral stability, amplitude decay (AD), and period elongation (PE) of the Wen method are studied. For comparison, the Generalized- $\alpha$ method [11] (the $\rho_{\infty}=0$, $\rho_{\infty}=0.5$, and $\rho_{\infty}=1.0$ cases), the Bathe method [16] (the $r=0.5$ and $r=2-\sqrt{2}$ cases), and the OTTBIF method [24] (the $\rho_{\infty}=0, \rho_{\infty}=0.5$, and $\rho_{\infty}=1.0$ cases) are also considered in this section. The parameters for these methods are selected according to the corresponding references.

3.1. Spectral Stability. The spectral characteristics of the time integration method are the basis for analyzing the stability and numerical dissipation properties. In structural dynamics, especially for nonlinear dynamics or transient problems of large structures, an excellent time integration method should have strong numerical dissipation for highfrequency modes, and the numerical damping for low frequency modes should be as small as possible.

In order to conduct stability analysis, a linear singledegree-of-freedom (SDOF) system is used, and the equation of the system is as follows:

$$
x+2 \xi \omega \dot{x}+\omega^{2} x=r(t)
$$

where $\xi, \omega$, and $r(t)$ are the damping ratio, the undamped angular frequency of the system, and the force excitation, respectively. $\omega$ satisfies $T=2 \pi / \omega$, where $T$ is the period of the system. By setting condition $r(t)=0$ and $\xi=0$ in equation (16), the recurrence formula of the Wen method for any undamped SDOF system can be obtained.

$$
\left[\begin{array}{c}
x_{t+\Delta t} \\
(\Delta t) \cdot \dot{x}_{t+\Delta t} \\
(\Delta t)^{2} \cdot x_{t+\Delta t}
\end{array}\right]=A\left[\begin{array}{c}
x_{t} \\
(\Delta t) \cdot \dot{x}_{t} \\
(\Delta t)^{2} \cdot x_{t}
\end{array}\right],
$$

where the expression of amplification matrix $\mathbf{A}$ can be found in [21].

The spectral radii of four implicit methods with different parameters are plotted in Figure 1, where $\Omega=\omega \Delta t=2 \pi \Delta t / T$. For the Wen method, the solutions of five parameter cases are considered. As shown in the figure, all cases are unconditionally stable, and all methods show numerical dissipation for high-frequency modes except the case G- $\alpha\left(\rho_{\infty}=1.0\right)$ and case OTTBIF $\left(\rho_{\infty}=1.0\right)$.

3.2. Accuracy Analysis. Generally speaking, the numerical dissipation and accuracy of time integration method are usually measured by the amplitude decay (AD) and the period elongation $(\mathrm{PE})$, respectively. The $\mathrm{AD}$ and $\mathrm{PE}$ results of the considered time integration methods are plotted in Figures 2 and 3, respectively. For the Wen method, it can achieve the lowest $\mathrm{AD}$ and $\mathrm{PE}$ in the case of $p=0.4$. Among the considered methods, the OTTBIF method has the lowest $\mathrm{AD}$ and PE results, namely, the highest accuracy for linear dynamics. And the AD and PE results of all Wen method cases are smaller than those of the Bathe method. The Generalized- $\alpha$ method shows the lowest accuracy.

\section{Numerical Examples}

In order to demonstrate performance of the Wen method on nonlinear dynamic analysis, four representative nonlinear dynamic problems are considered in this section. First, two classical nonlinear systems are tested to illustrate solution accuracy of the Wen method. Then an eleven-story shear building and a space truss subjected to seismic load are considered. The suggested algorithm parameters $p=1 / 3$ and $p=0.4$ of the Wen method for linear dynamics are adopted for analysis. For comparison, the single-step Generalized- $\alpha$ method (the $\rho_{\infty}=0$ case) [11], the two substeps' Bathe method (the $r=0.5$ case) [16], and the three substeps' OTTBIF method (the $\rho_{\infty}=0$ case) [24] are considered. The parameters of three methods are selected according to the corresponding references. In order to achieve almost the same time cost for each method, different methods use different time steps. For comparison, the same time step for all methods is also considered. 


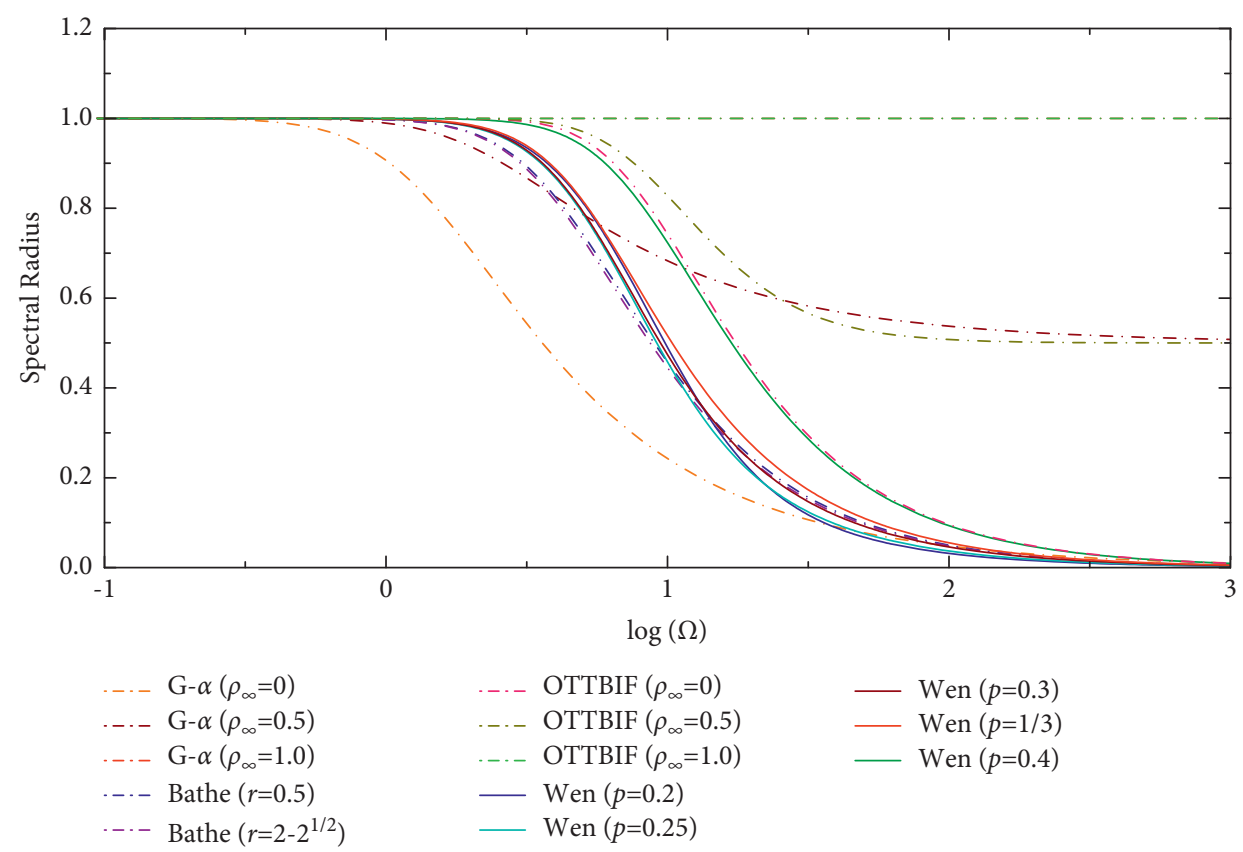

FIgURE 1: Spectral radii of various methods for undamped system $(\xi=0)$.
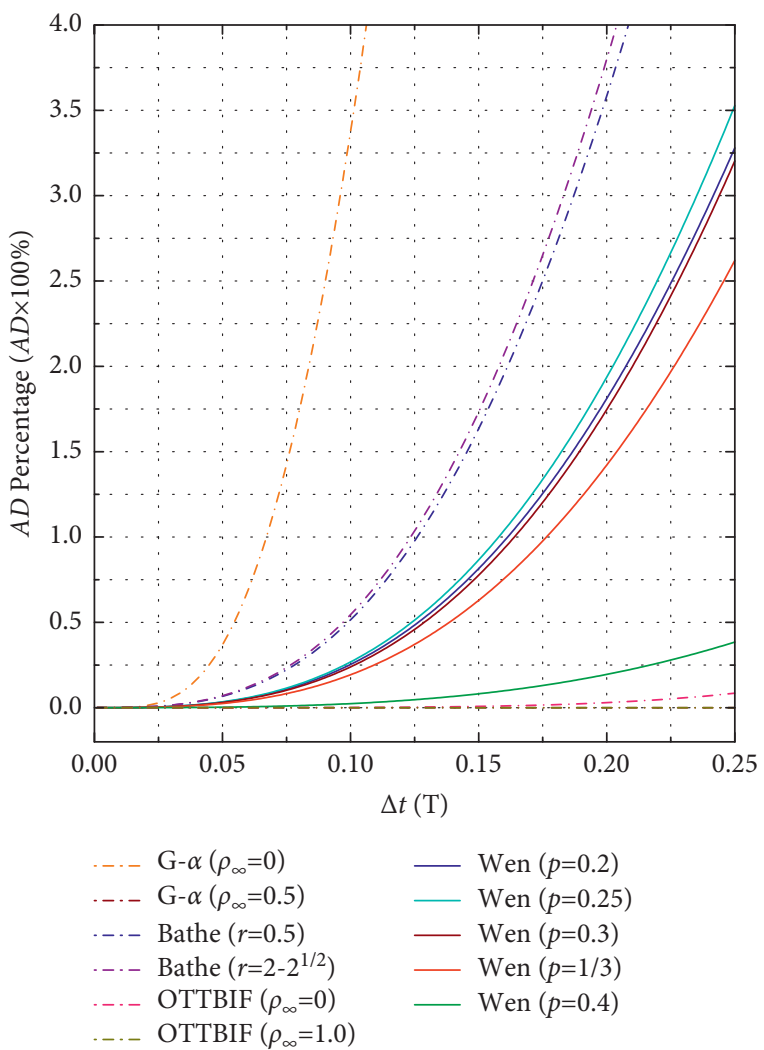

FIgURE 2: The percentage AD results of various methods.
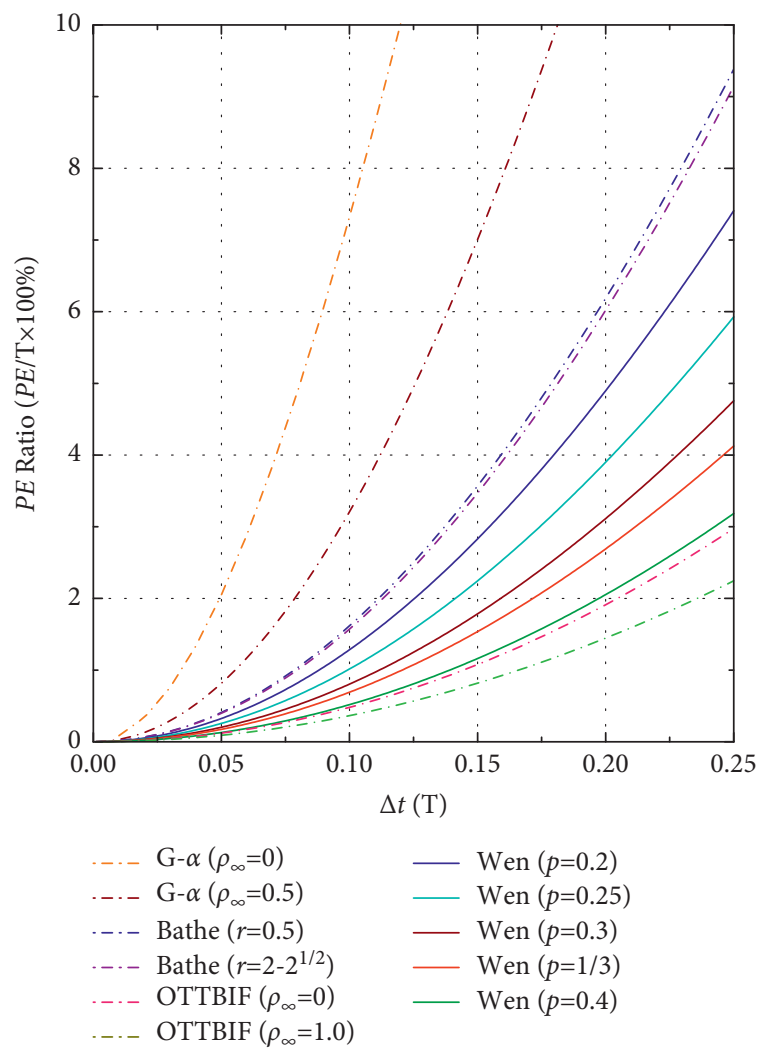

Figure 3: The percentage PE results of various methods. 
4.1. Van der Pol's Equation. A nonlinear equation called Van der Pol' equation is considered here [26]. The equation is written as

$$
\left(1+x^{2}\right) x+\left(c+x^{2}\right) \dot{x}+x=0
$$

where the constant $c$ represents the damping coefficient of the Van der Pol's equation and is negative here. The value of $c$ and the initial conditions of the system are given.

$$
\begin{aligned}
c & =-0.2, \\
x(0) & =-0.02, \\
\dot{x}(0) & =0 .
\end{aligned}
$$

The displacement, velocity, and acceleration results of the system are plotted in Figures 4-9, respectively. The quasi-exact solutions shown in the figures are obtained from the explicit Bathe method [27] by using very small time step $\Delta t=1 \times 10^{-5} \mathrm{~s}$. As shown in the figures, different time steps are adopted for different time integration methods to ensure roughly the same time cost.

Figures 4-6 show that, among all considered methods and cases with different time steps, the $p=0.4$ case of the Wen method shows highest solution accuracy. The accuracy of the OTTBIF method is slightly lower than that of the Wen method $(p=0.4)$. The Bathe method and the Wen method $(p=1 / 3)$ have desirable accuracy, but it is lower than that of the OTTBIF method and the Wen method $(p=0.4)$. In addition, although the Generalized- $\alpha$ method adopts a relatively small time step, it shows lower accuracy than that of other composite time integration methods. In dsl-9, the same time step is adopted to compare different methods. It is observed that accuracy of the OTTBIF method and the Wen method $(p=0.4)$ is much higher than the Generalized- $\alpha$ method, the Bathe method, and the Wen method $(p=1 / 3)$. In Table 1, time cost of all methods in time history of $0-500 \mathrm{~s}$ is given. The Generalized- $\alpha$ method with $\Delta t=0.12 \mathrm{~s}$ and $\Delta t=0.36 \mathrm{~s}$, respectively, has the longest and shortest elapsed time among all considered methods. Time costs of the Bathe method $(\Delta t=0.24 \mathrm{~s})$, the OTTBIF method $(\Delta t=0.36 \mathrm{~s})$, and the Wen method ( $p=1 / 3$ or $0.4, \Delta t=0.36 \mathrm{~s}$ ) are very close. Combined with the calculation accuracy, the Wen method $(p=0.4)$ and the OTTBIF method have higher computational efficiency than other methods.

4.2. A Bead Sliding on the Wire. In the fixed vertical $(x, y)$ plane as shown in Figure 10, a bead of mass $m$ slides on the smooth wire (the frictional force is neglected). The curve of wire can be expressed by the equation $y=x^{2}$. The motion equation of bead in $x$ direction is given.

$$
\left(1+4 x^{2}\right) x+4 x \dot{x}^{2}+2 g x=0,
$$

where $g$ is the acceleration of gravity. The initial conditions of the system are $(0)=-5, x(0)=0$. The quasi-exact solutions are calculated by the explicit Bathe method with time step $\Delta t=1 \times 10^{-5} \mathrm{~s}$. In Figures $11-14, \Delta t=0.01 \mathrm{~s}$ and $0.02 \mathrm{~s}$ are, respectively, selected for the Generalized- $\alpha$ and Bathe methods, while $\Delta t=0.03 \mathrm{~s}$ is adopted for the OTTBIF and
Wen methods. In Figures 15-17, all methods adopt the same time step $\Delta t=0.03 \mathrm{~s}$.

The displacement results of various methods for time duration $0-50 \mathrm{~s}$ are shown in Figure 11. It is observed that the results of the Generalized- $\alpha$ method are divergent. The displacement, velocity, and acceleration responses of the bead for time duration 180-200s are plotted in dslf-14, respectively. The results show that the Wen method in case $p=0.4$ achieves highest accuracy among all considered methods. In addition, accuracy of the Wen method $(p=1 / 3)$ and the OTTBIF method is lower than that of the Bathe method, and the energy dissipation of the OTTBIF method is obviously larger than that of other methods. Table 2 illustrates the elapsed time of all methods at $t=200 \mathrm{~s}$. The results illustrate that the Wen method in case $p=0.4$ has the lowest energy decay and consumes less time cost than the OTTBIF method. The Bathe method $(\Delta t=0.03 \mathrm{~s})$ needs less computation time than other methods, but begets the largest proportion of energy dissipation. In Figures 15-17, when the same time step $\Delta t=0.03 \mathrm{~s}$ is used for all methods, the Wen method $(p=0.4)$ displays far higher solution accuracy than other methods.

4.3. Nonlinear Structural Seismic Response Analysis. Here two nonlinear structural systems under seismic load are tested. The two considered structural systems are an elevenstory shear building and a space truss. The Bouc-Wen hysteresis model [28] is employed for the nonlinear dynamic analysis of these two structural systems. We adopt the Rayleigh damping to form damping matrix, and the damping ratios are 3\% and 5\% for the first and second vibration modes, respectively. Since the first two modes are intrinsically selected by experience, the numerical dissipation properties of the considered methods cannot be reflected in these two examples.

Different time steps are adopted for all time integration methods to ensure roughly the same time cost for the dynamic analysis. The quasi-exact solution is obtained using the Bathe method $(r=0.5)$ with very small time step $\Delta t=1 \times 10^{-5}$ s. For composite time integration methods, the required loads at the substeps are obtained by employing linear interpolation of two adjacent seismic acquisition load values.

4.3.1. An Eleven-Story Shear Building. The eleven-story shear building shown in Figure 18 is subjected to the 1940 EI Centro North-South seismic load (see Figure 19). The system is idealized as a simple shear model and has 11 degrees of freedom. The lumped mass and shear stiffness of each story are illustrated in Figure 18. The first story (isolation layer) of the structural system adopts Bouc-Wen hysteresis model [28] (see Figure 20). More details of the structure can be found in [29]. The acquisition frequency of seismic load is $50 \mathrm{~Hz}$, and we intercept $30 \mathrm{~s}$ of the seismic load for dynamic analysis. The curve of seismic acceleration load in terms of time is shown in Figure 19.

The motion equation of linear structural system under seismic load can be expressed as [30] 


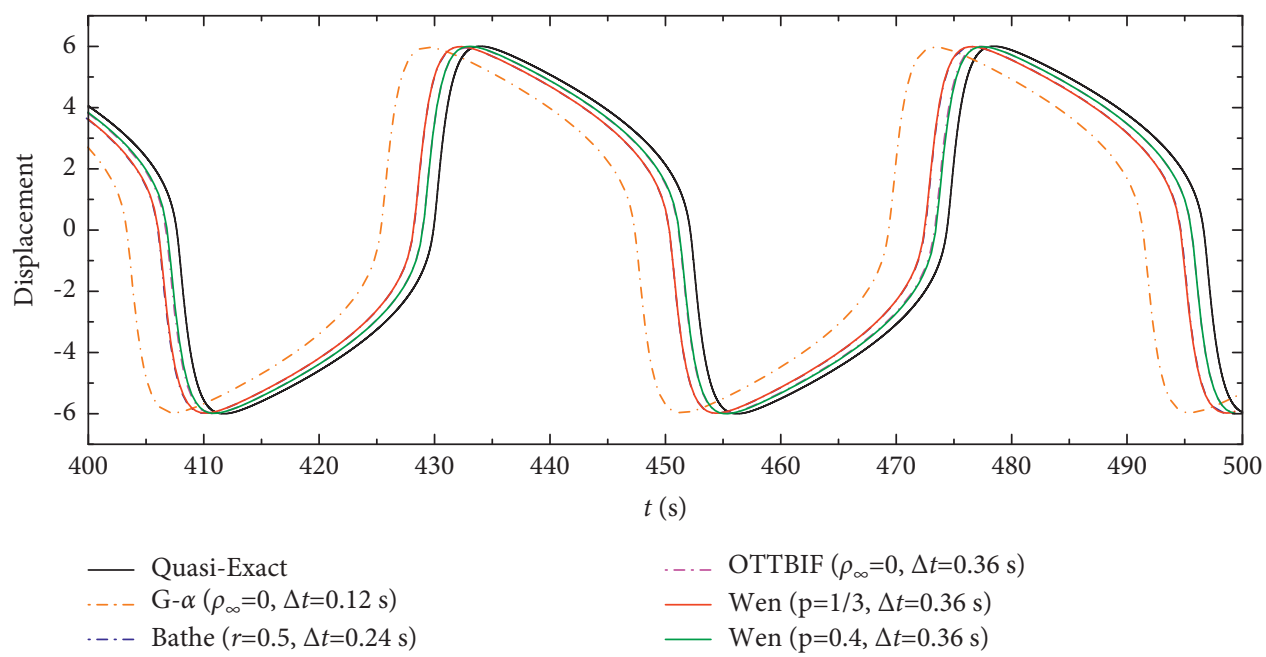

FIgURE 4: The displacement results of various methods with different time steps for example 4.1.

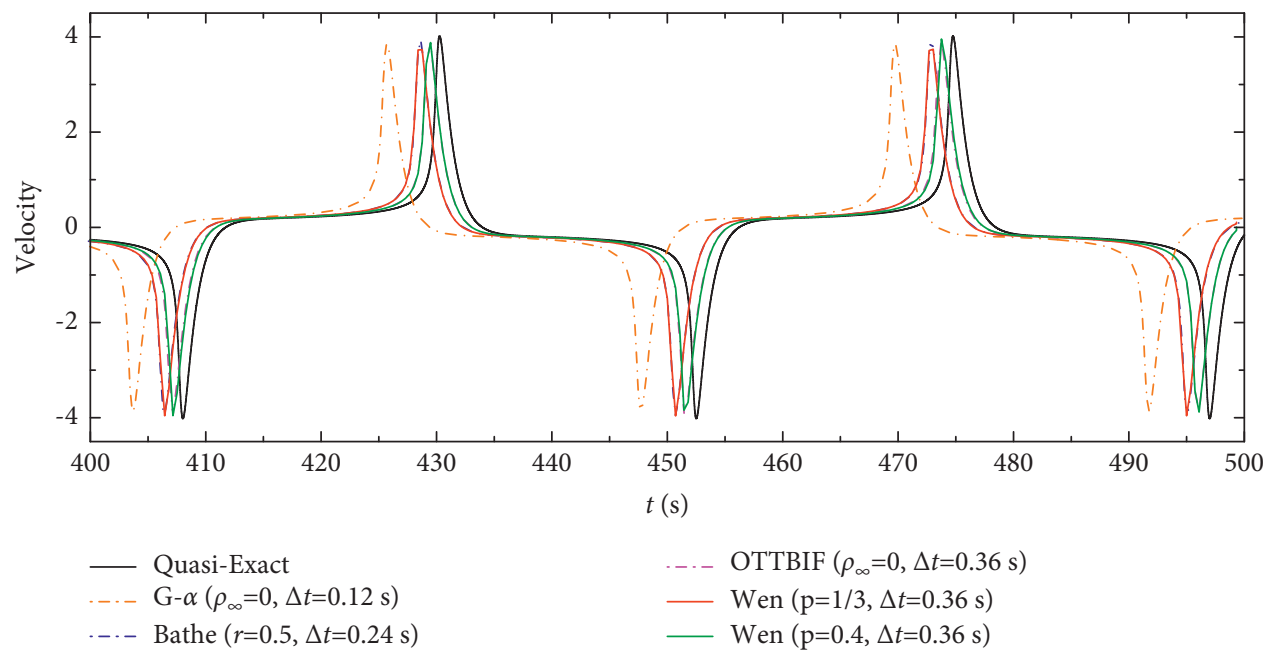

FIGURE 5: The velocity results of various methods with different time steps for example 4.1.

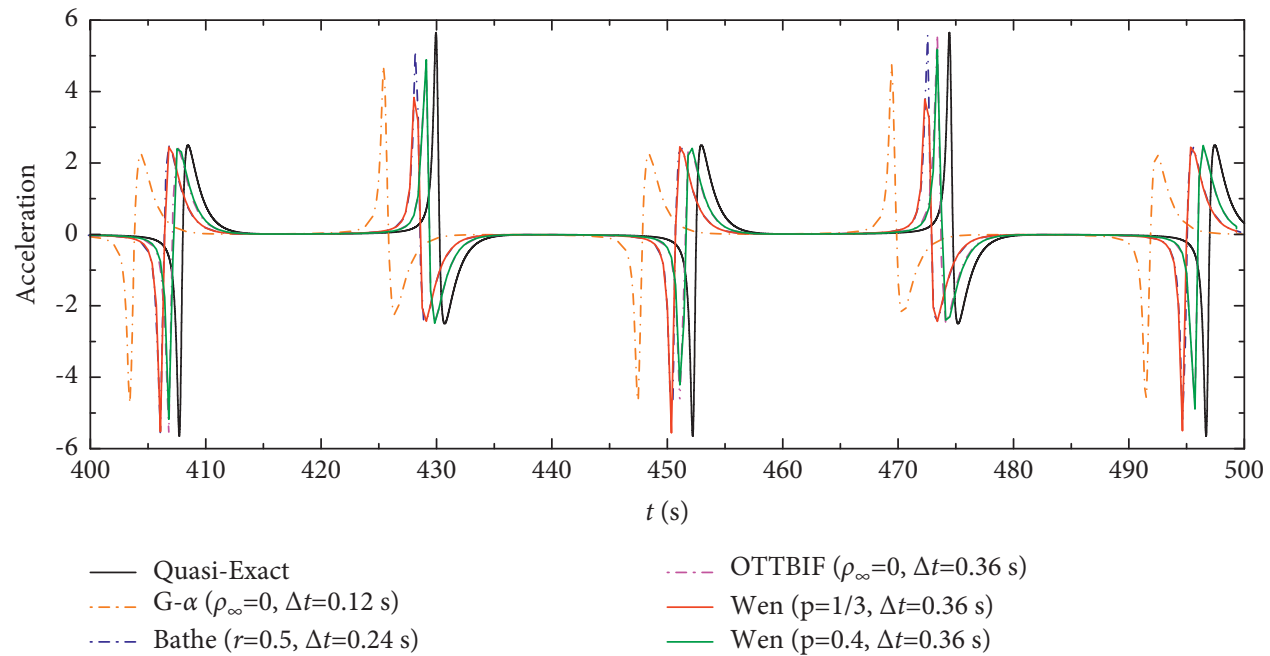

FIgure 6: The acceleration results of various methods with different time steps for example 4.1. 


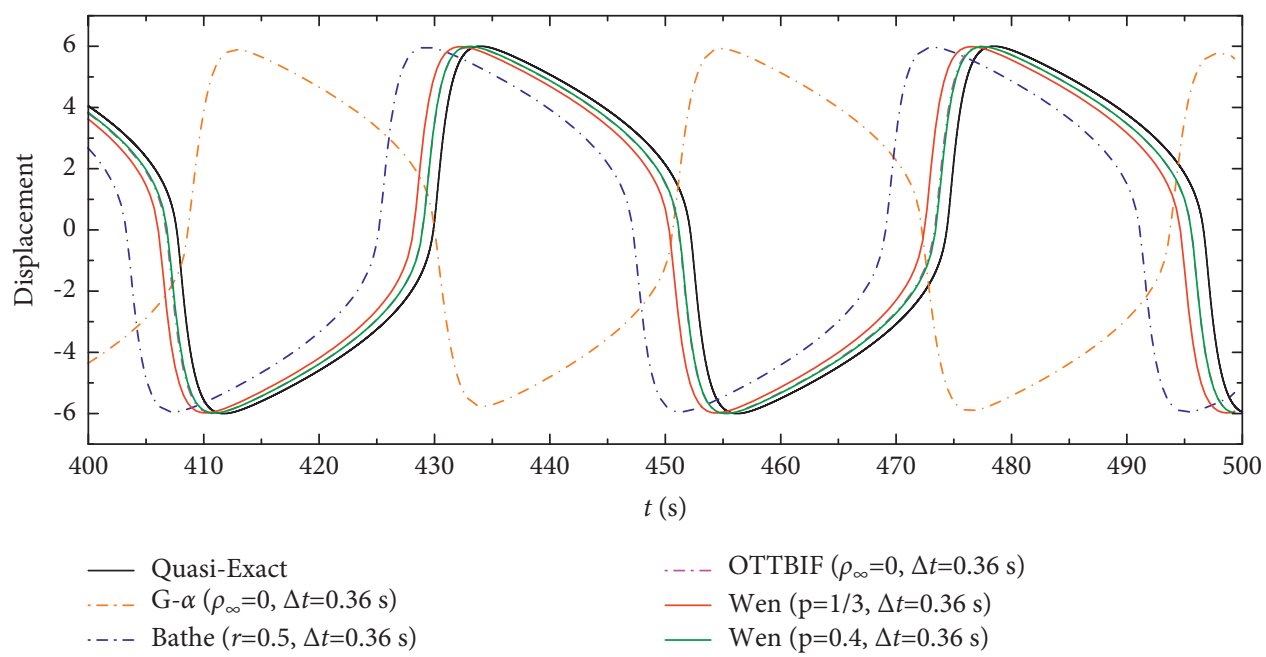

Figure 7: The displacement results of various methods with the same time step for example 4.1.

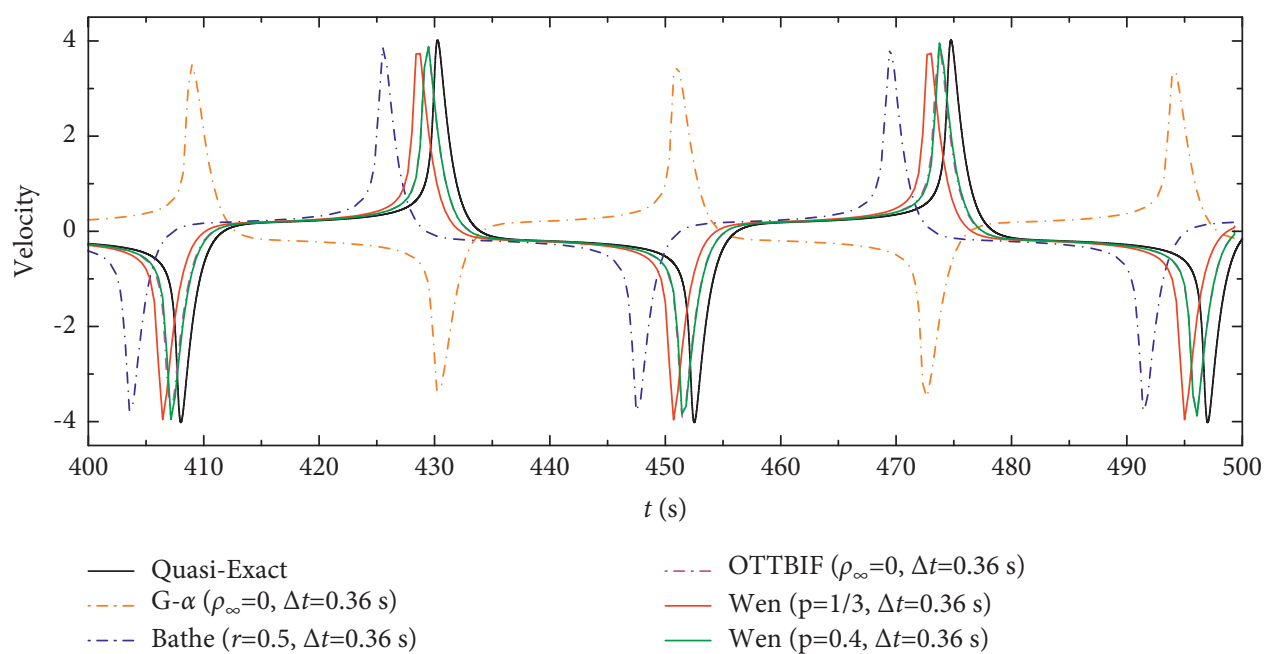

FIGURE 8: The velocity results of various methods with the same time step for example 4.1.

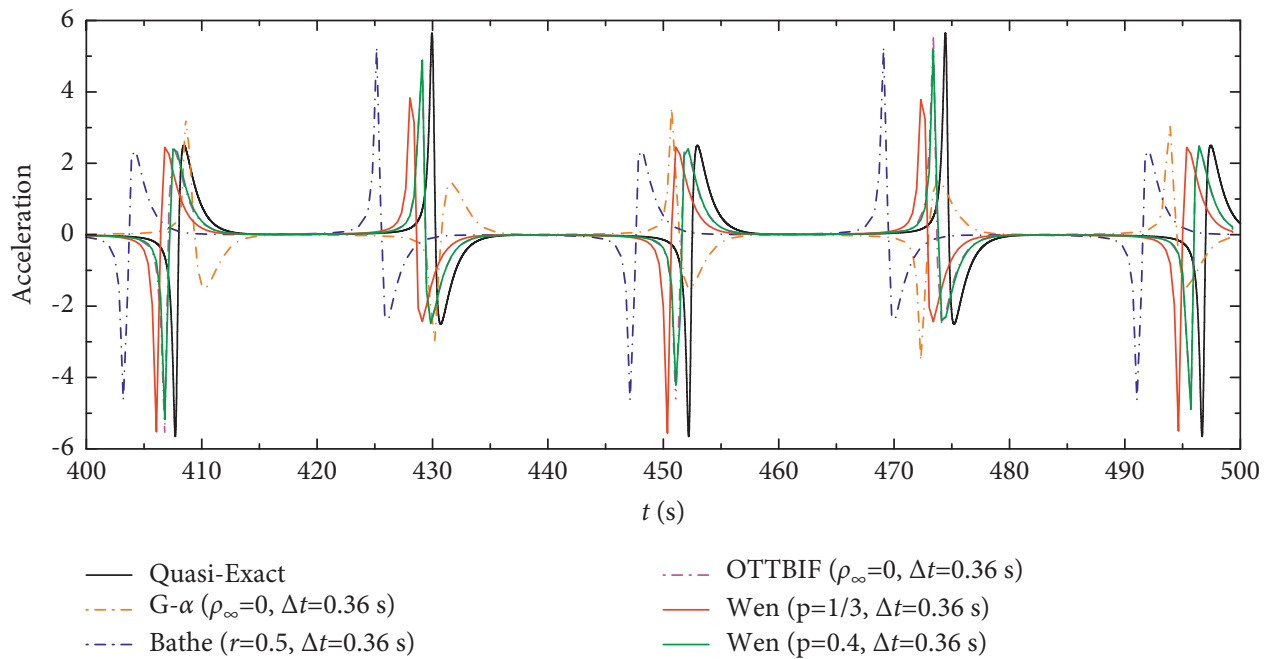

Figure 9: The acceleration results of various methods with the same time step for example 4.1. 
TABLE 1: Time cost of various methods in time history of $0-500 \mathrm{~s}$, for example 4.1

\begin{tabular}{|c|c|c|c|c|c|c|c|}
\hline Method & G- $\alpha\left(\rho_{\infty}=0\right)$ & $\mathrm{G}-\alpha\left(\rho_{\infty}=0\right)$ & Bathe $(r=0.5)$ & Bathe $(r=0.5)$ & OTTBIF $\left(\rho_{\infty}=0\right)$ & Wen $(p=1 / 3)$ & Wen $(p=0.4)$ \\
\hline hime sexp (o) & 0.12 & 0.36 & 0.24 & 0.36 & 0.36 & 0.36 & 0.36 \\
\hline The elapsed time (s) & 120.3 & 44.3 & 97.1 & 65.1 & 99.4 & 95.4 & 95.4 \\
\hline
\end{tabular}

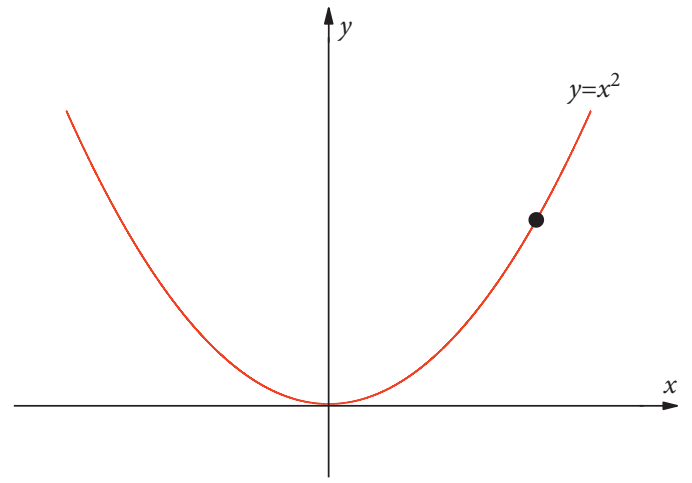

Figure 10: A bead and the wire.

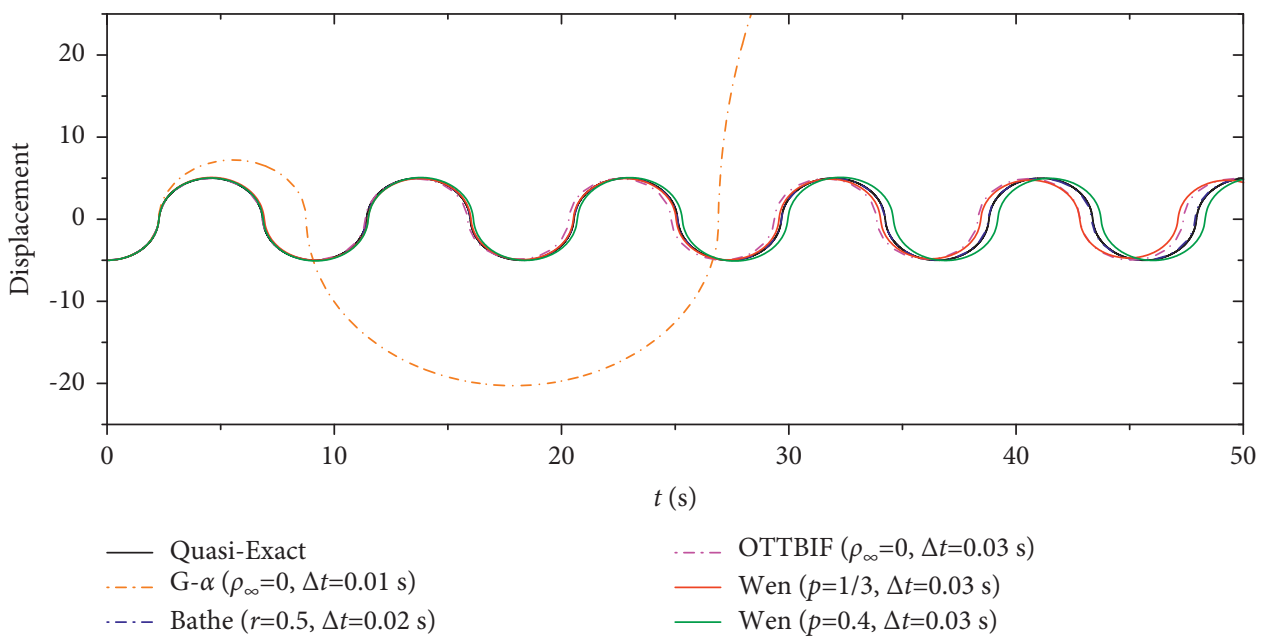

FIgURE 11: The displacement results of bead for time duration 0-50s.

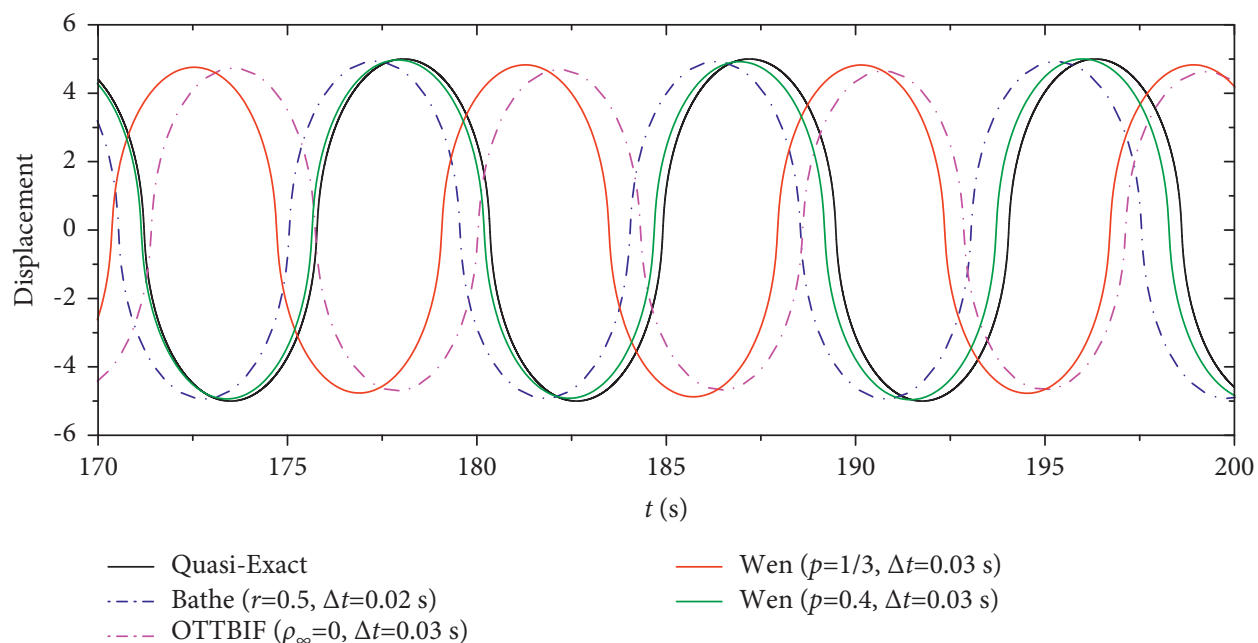

Figure 12: The displacement results of bead for time duration 180-200s. 


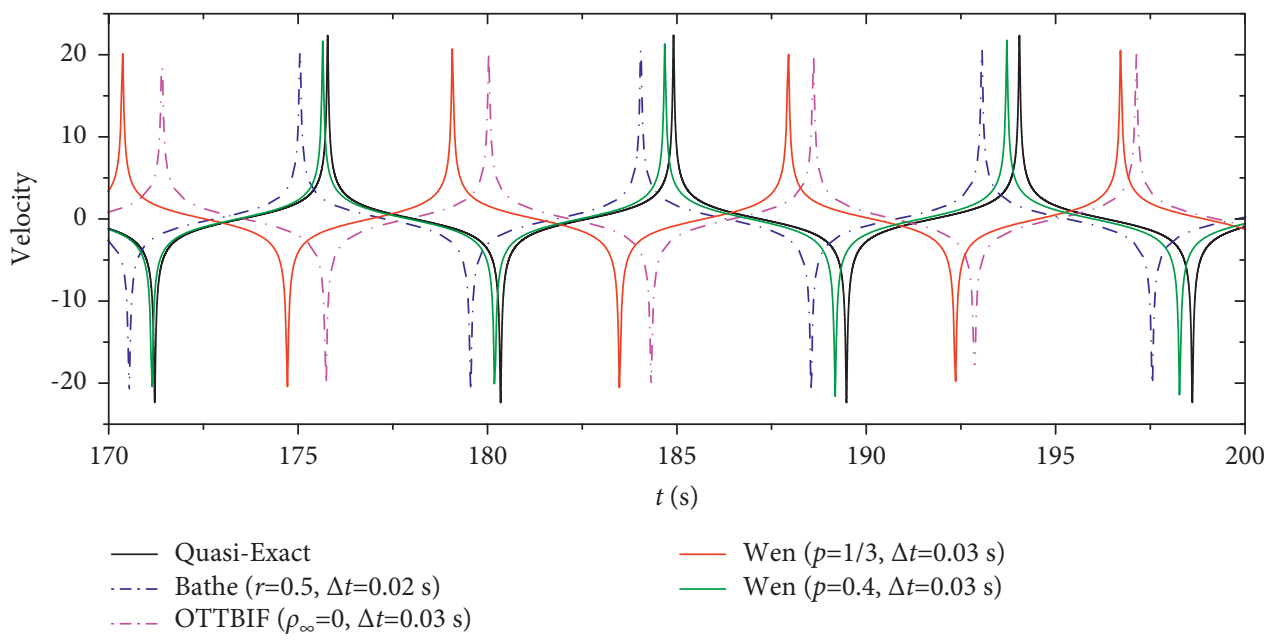

Figure 13: The velocity results of bead for time duration 180-200 s.

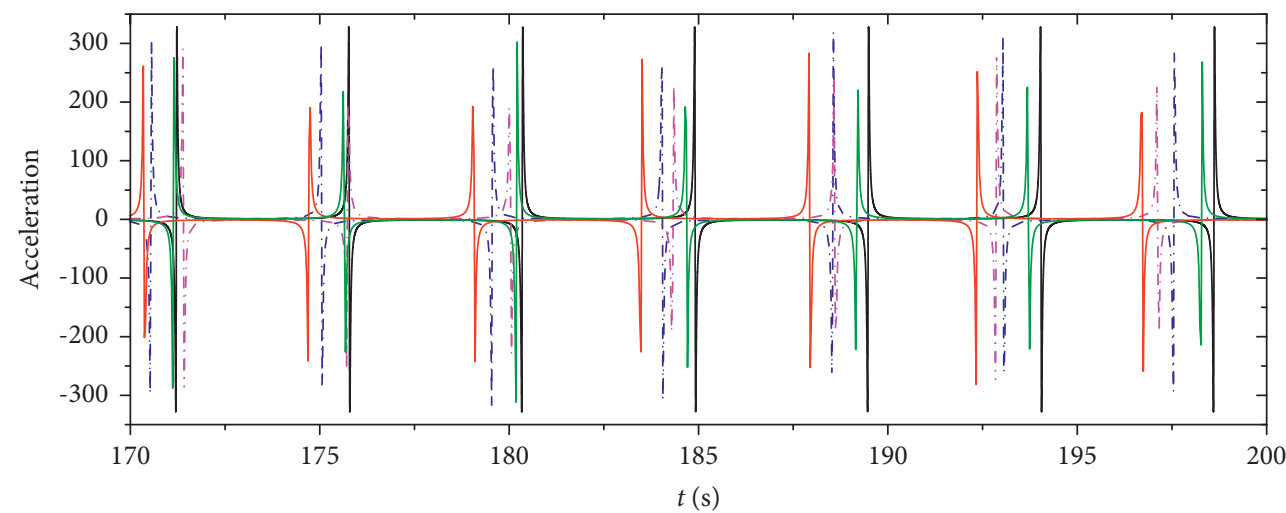

_ Quasi-Exact
$\ldots$ Bathe $(r=0.5, \Delta t=0.02 \mathrm{~s})$
$\ldots \ldots$ OTTBIF $\left(\rho_{\infty}=0, \Delta t=0.03 \mathrm{~s}\right)$

Wen $(p=1 / 3, \Delta t=0.03 \mathrm{~s})$
Wen $(p=0.4, \Delta t=0.03 \mathrm{~s})$

Figure 14: The acceleration results of bead for time duration 180-200 s.

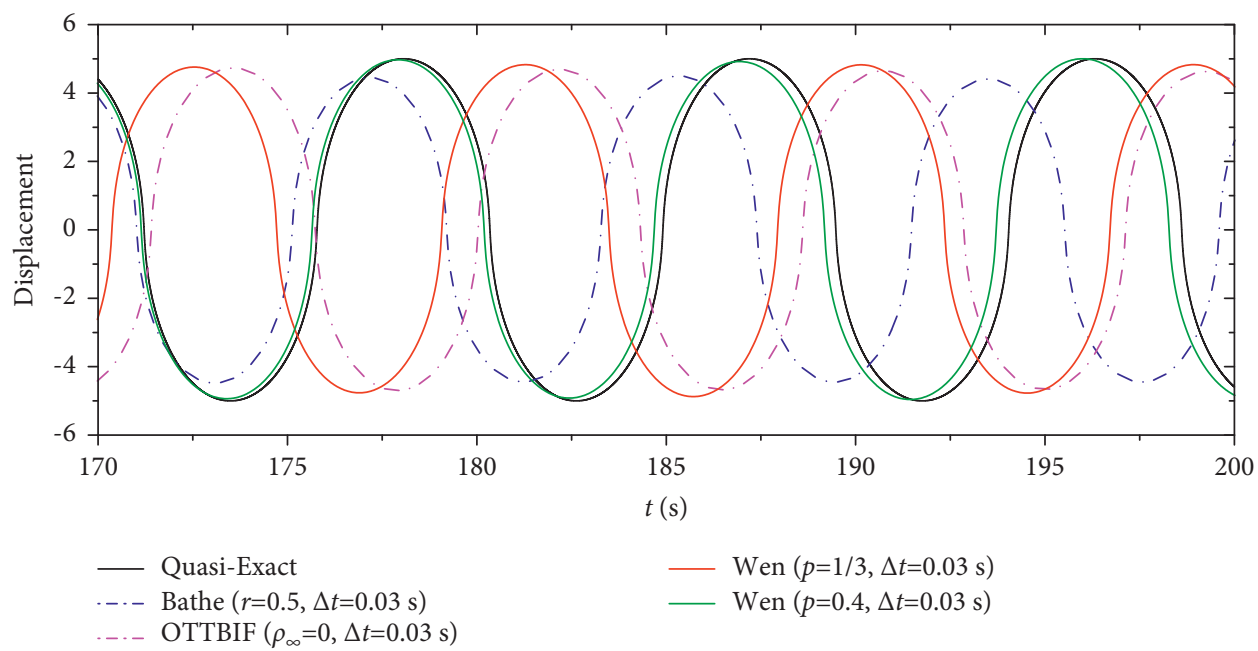

FIgURE 15: The displacement results of various methods with the same time step $\Delta t=0.03 \mathrm{~s}$. 


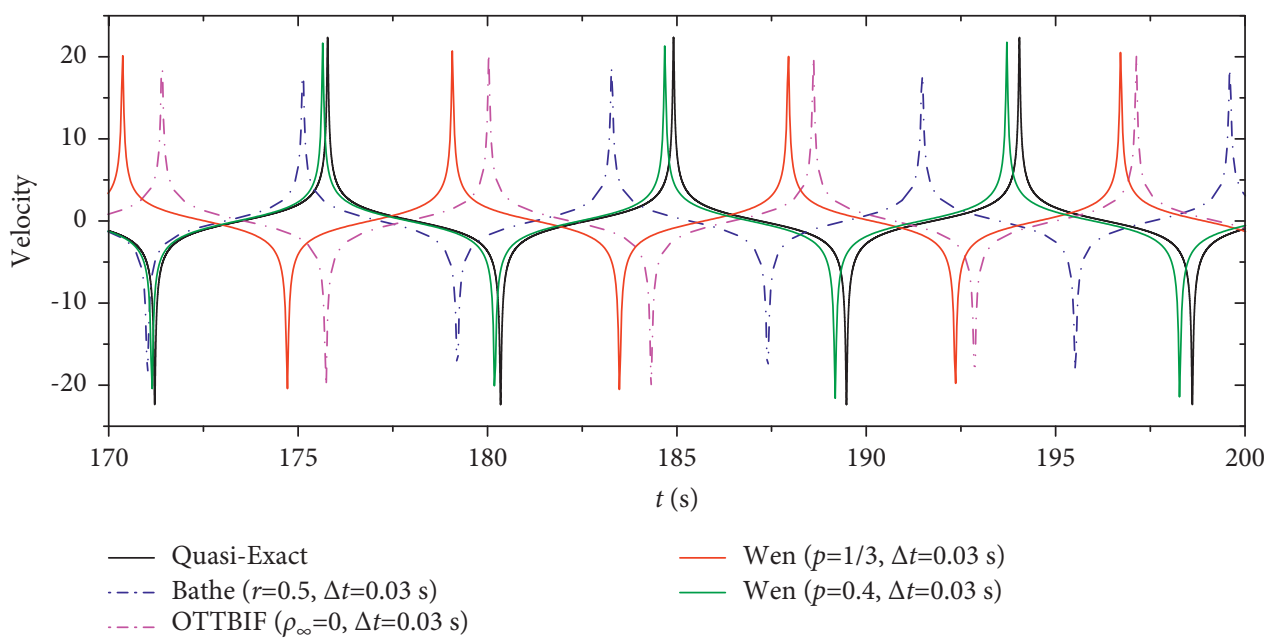

FIgURE 16: The velocity results of various methods with the same time step $\Delta t=0.03 \mathrm{~s}$.

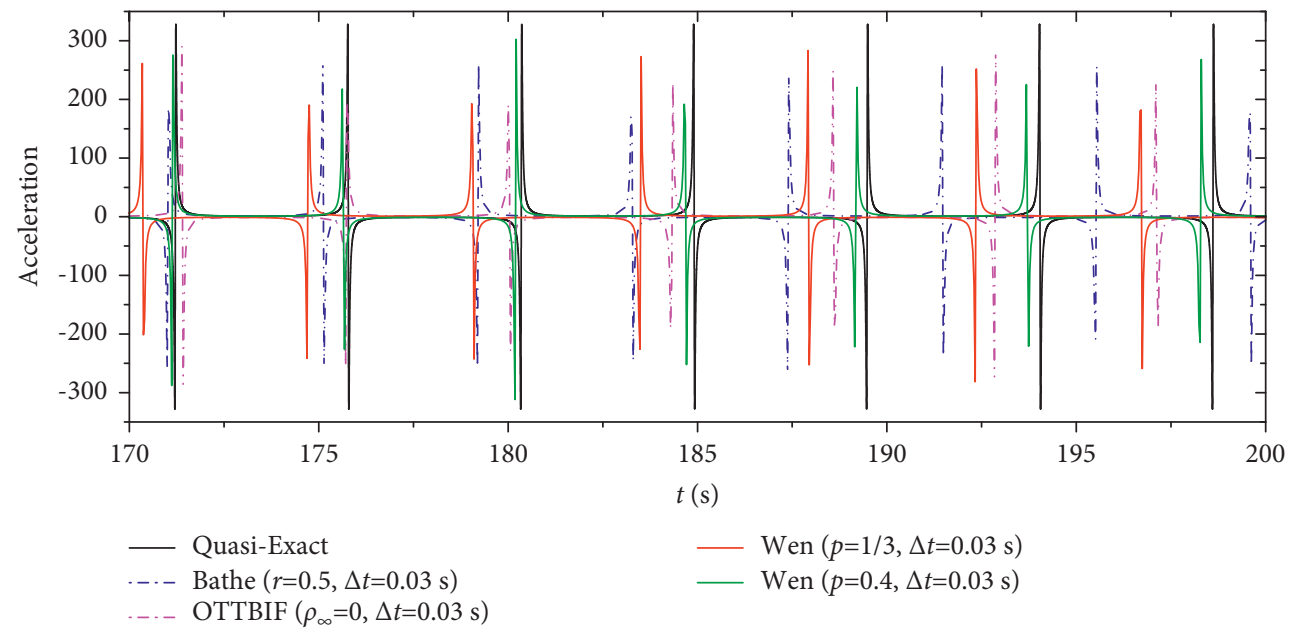

Figure 17: The acceleration results of various methods with the same time step $\Delta t=0.03 \mathrm{~s}$.

TABLe 2: The energy dissipation and time cost of various methods for example 4.2.

\begin{tabular}{|c|c|c|c|c|c|c|}
\hline Method & Bathe $(r=0.5)$ & Bathe $(r=0.5)$ & OTTBIF $\left(\rho_{\infty}=0\right)$ & Wen $(p=1 / 3)$ & \multicolumn{2}{|c|}{ Wen $(p=0.4)$} \\
\hline Time step (s) & 0.02 & 0.03 & 0.03 & 0.03 & \\
\hline Elapsed time $(s)$ & 837.7 & 481.4 & 737.51 & 699.9 & \\
\hline Energy dissipation percentage & 3.2 & 18.9 & 14.36 & 6.74 & \multicolumn{2}{|c|}{0.49} \\
\hline \multicolumn{2}{|c|}{$M X+C \dot{X}+K X=-M R X_{g}$} & $(21)$ & $M X+C \dot{X}+(K$ & ) $X+\alpha Z=-$ & & $(22$ \\
\hline \multicolumn{3}{|c|}{$\begin{array}{l}\text { where } M, C \text {, and } K \text { are mass, damping, and stiffness } \\
\text { matrices of the considered system. } X_{g} \text { is the vector of } \\
\text { ground motion acceleration. } R \text { is the influence vector, } \\
\text { which defines the displacement of the system when the } \\
\text { foundation produces static unit displacement in the di- } \\
\text { rection of load excitation. } \\
\text { The motion equation of the nonlinear part of the system } \\
\text { can be written as follows: }\end{array}$} & \multicolumn{4}{|c|}{$\begin{array}{l}\text { where } \alpha \text { is the peak value of inelastic force and satisfies } \\
\alpha=Q_{y}\left(1-k_{\text {post }} / k_{\text {pre }}\right) . Q_{y}, k_{\text {pre }} \text {, and } k_{\text {post }} \text { are the total force } \\
\text { at the critical point of yield, the stiffness before yield, and } \\
\text { stiffness after yield, respectively; } A, \beta \text {, and } \gamma \text { satisfy } \\
A=2 \beta=2 \gamma=k_{\text {pre }} / Q_{y} \text {. The hysteretic restoring force } Z \text { of } \\
\text { each time step is solved by Runge-Kutta method [31]. }\end{array}$} \\
\hline
\end{tabular}




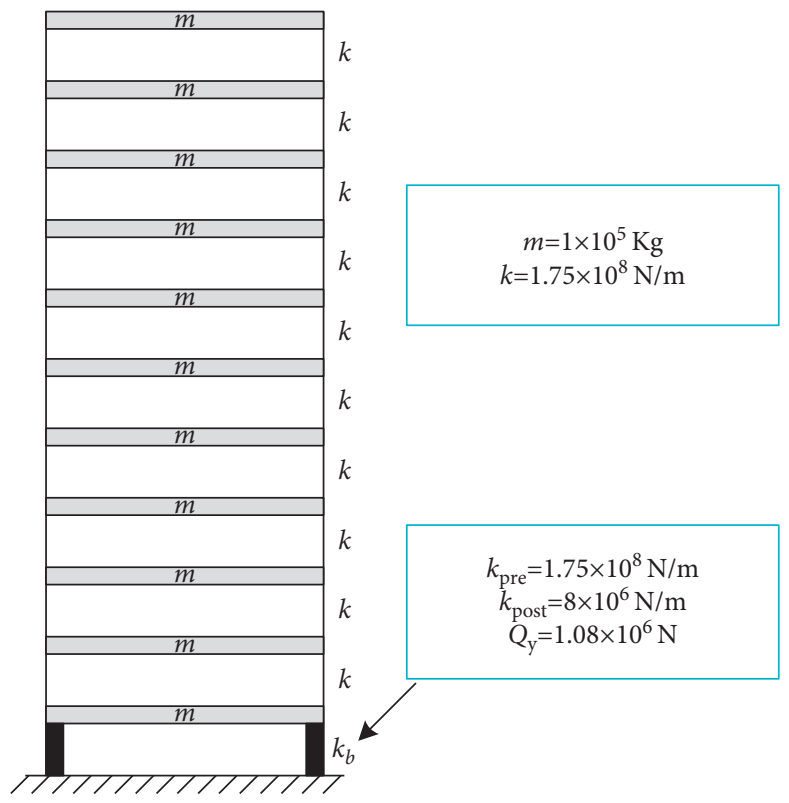

FIGURE 18: Eleven-story shear building.

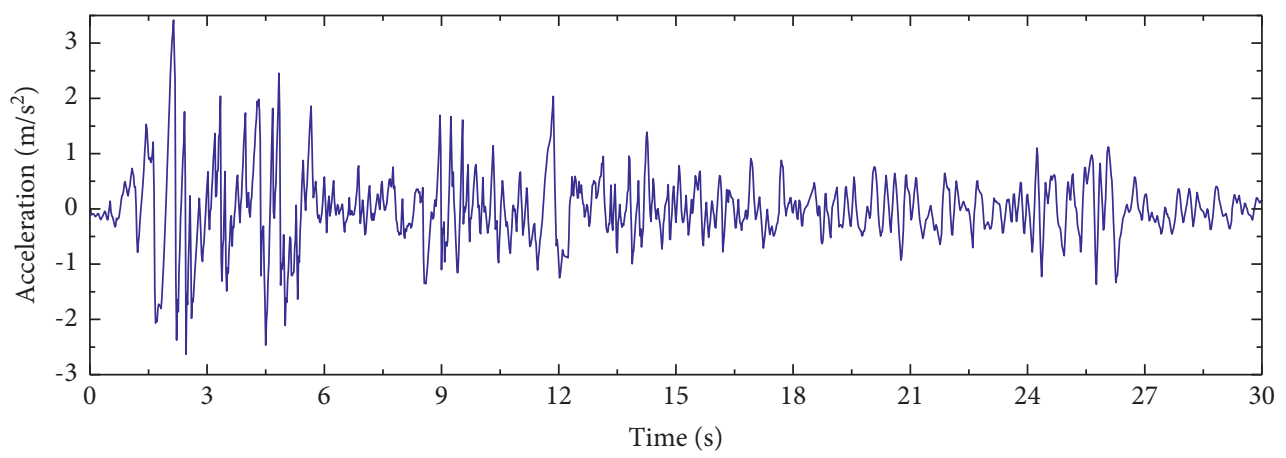

FIgURE 19: The North-South direction of EI Centro seismic load curve.

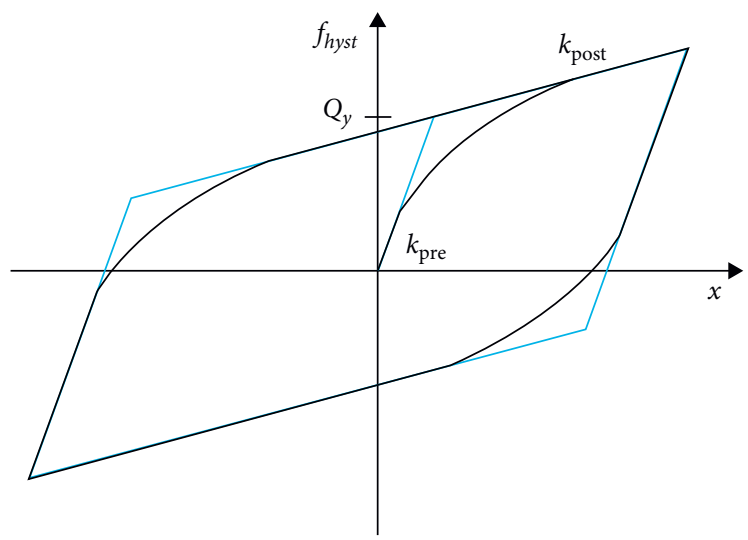

- Bouc-Wen

Figure 20: Bouc-Wen hysteresis model. 


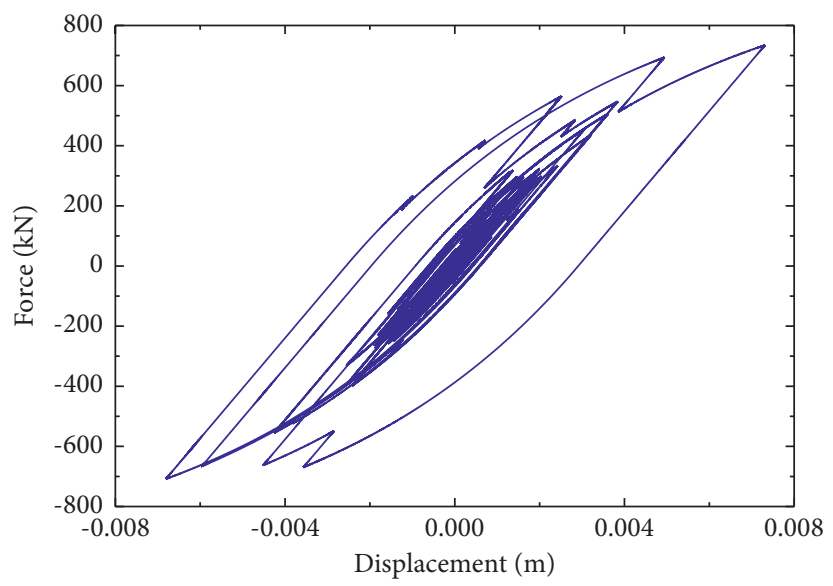

FIGURE 21: The hysteretic force of the bottom element.

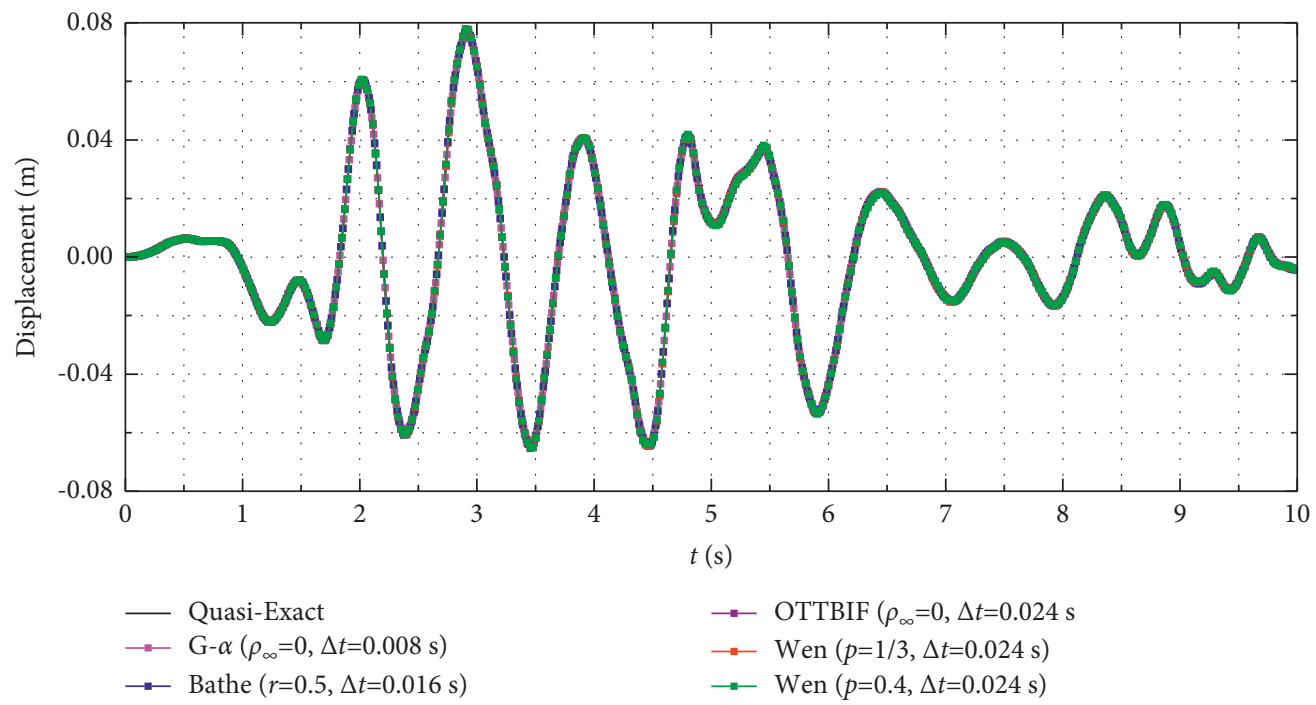

(a)

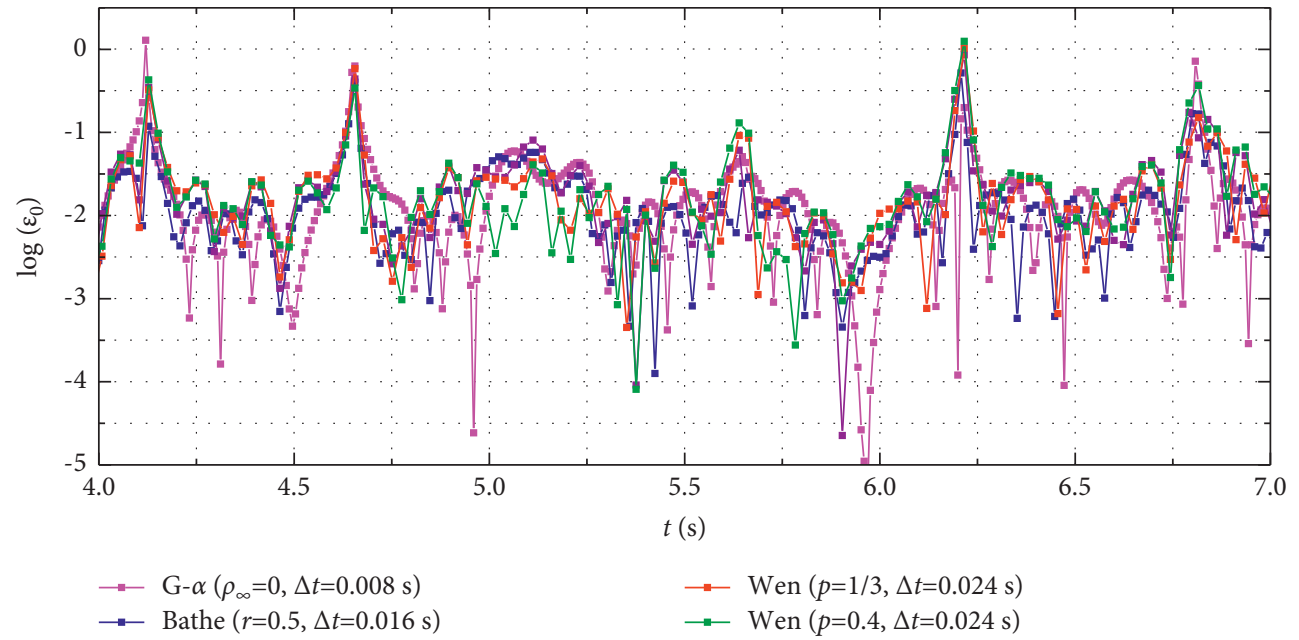

(b)

FIGURE 22: The displacement results and relative errors of top story obtained from various methods. (a) Displacement results of 0-10 s. (b) The relative errors between 4 and $7 \mathrm{~s}$. 


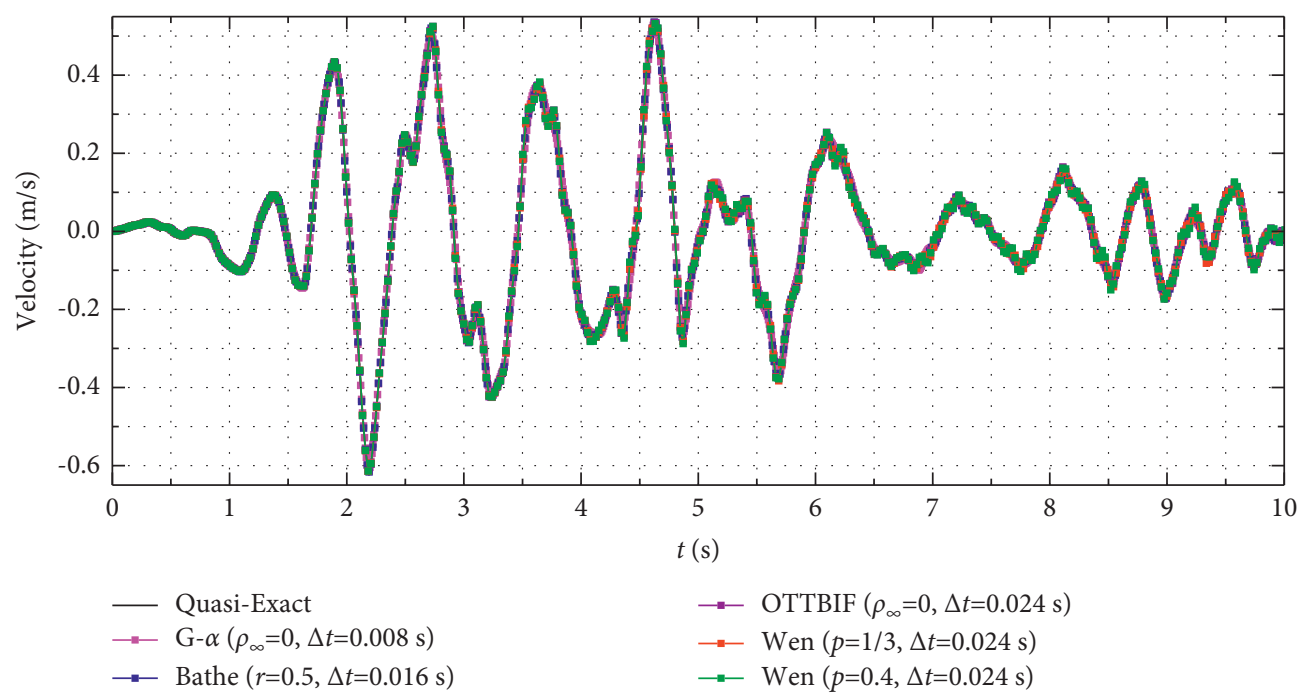

(a)

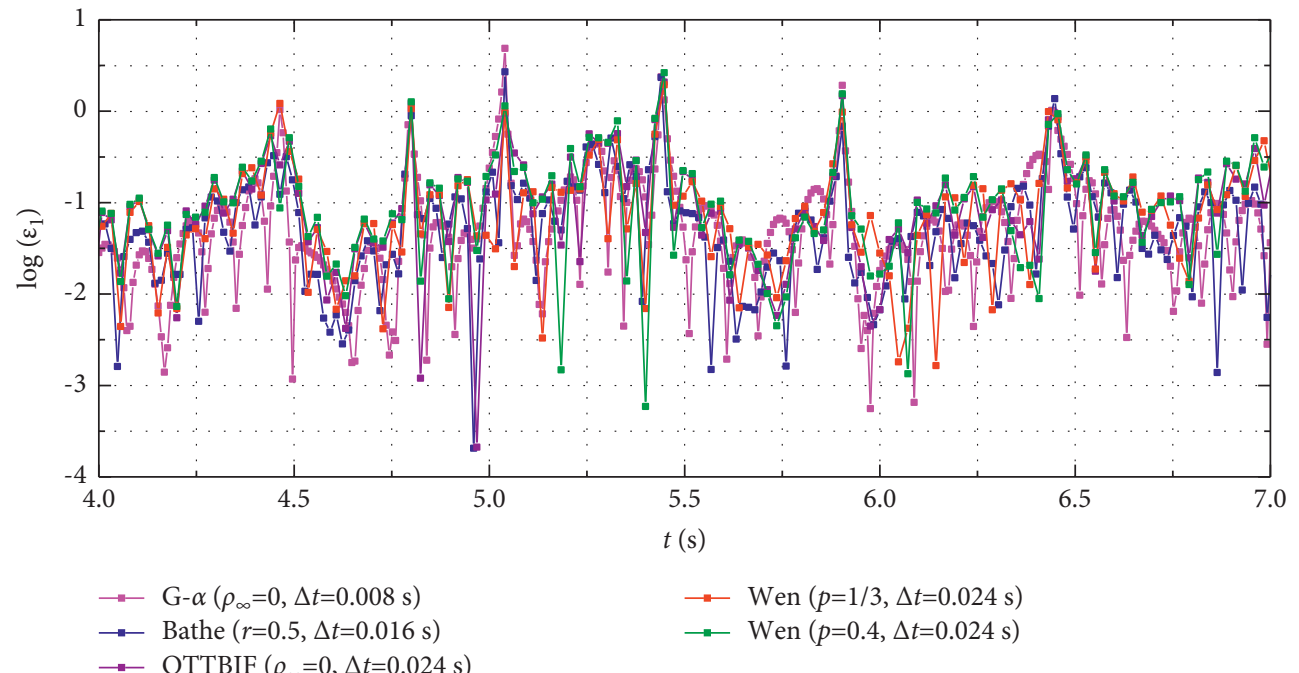

(b)

FIGURE 23: The velocity results and relative errors of top story obtained from various methods: (a) Velocity results of $0-10 \mathrm{~s}$. (b) The relative errors between 4 and $7 \mathrm{~s}$.

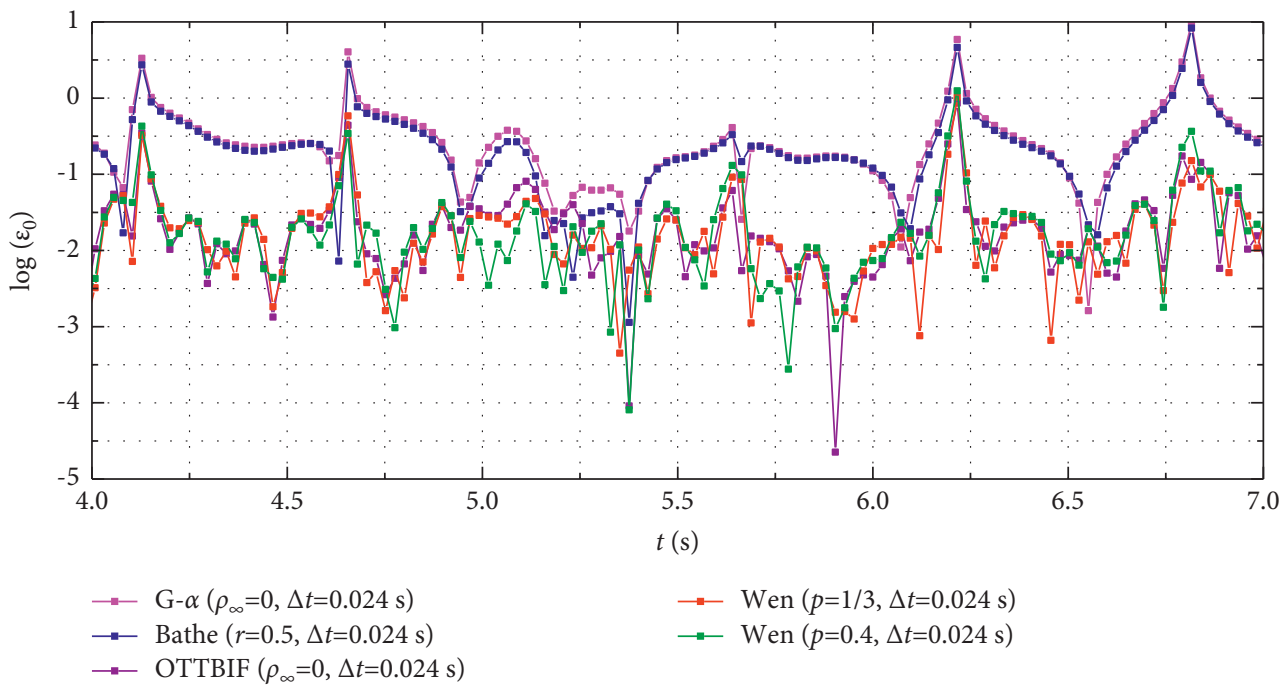

FIgURE 24: The displacement errors of top story obtained from various methods with the same time step $\Delta t=0.024 s$. 


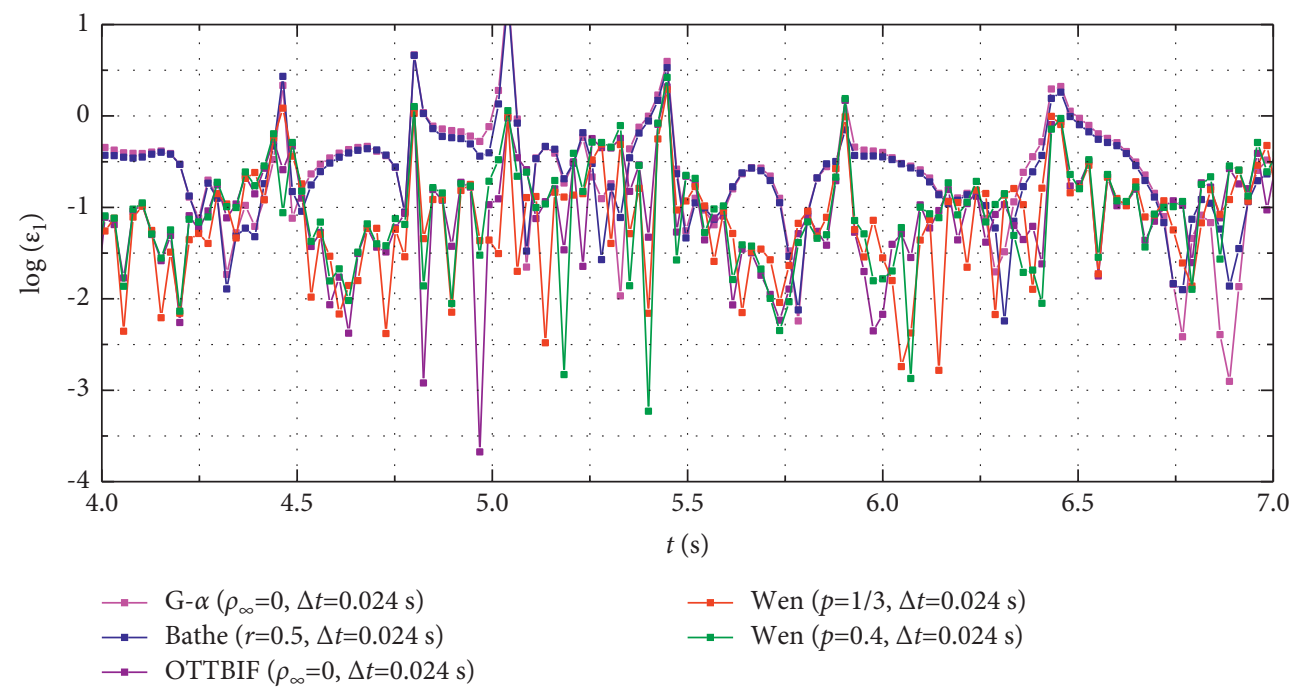

FIgURE 25: The velocity errors of top story obtained from various methods with the same time step $\Delta t=0.024 s$.

TABle 3: Time cost of various methods in time history of $0-30 \mathrm{~s}$ for example 4.3.1.

\begin{tabular}{|c|c|c|c|c|c|c|c|}
\hline Method & $\mathrm{G}-\alpha\left(\rho_{\infty}=0\right)$ & G- $\alpha\left(\rho_{\infty}=0\right)$ & Bathe $(r=0.5)$ & Bathe $(r=0.5)$ & OTTBIF $\left(\rho_{\infty}=0\right)$ & Wen $(p=1 / 3)$ & Wen $(p=0.4)$ \\
\hline Time Step (s) & 0.008 & 0.024 & 0.016 & 0.024 & 0.024 & 0.024 & 0.024 \\
\hline Elapsed time (s) & 0.430 & 0.152 & 0.221 & 0.160 & 0.184 & 0.180 & 0.180 \\
\hline
\end{tabular}

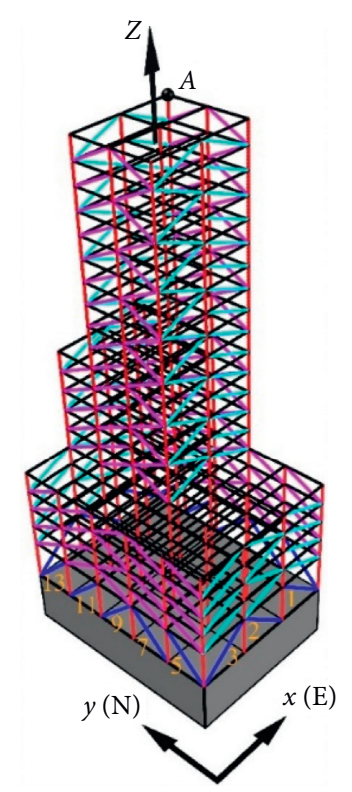

Figure 26: A space truss.

The hysteretic restoring force curves of the bottom story are shown in Figure 21. It can be observed that the internal force exceeds the bottom story yield limit. In Figure 22, the displacement results and errors of top story obtained from various methods are illustrated. The velocity results and errors are plotted in Figure 23. For clarity, the displacement and velocity during $0-10 \mathrm{~s}$ are analyzed. It is noticed that all four methods can achieve close accuracy. In Figures 24 and
25 , the displacement and velocity errors of different methods with the same time step $\Delta t=0.024 \mathrm{~s}$ are, respectively, plotted. It is observed that the errors of the Wen method and the OTTBIF method are much smaller than those of the Bathe method and the Generalized- $\alpha$ method. In Table 3, time cost of various methods with different time step in time history of $0-30 \mathrm{~s}$ is given. The elapsed time of the Wen method and the OTTBIF method with $\Delta t=0.024 \mathrm{~s}$ is slightly 


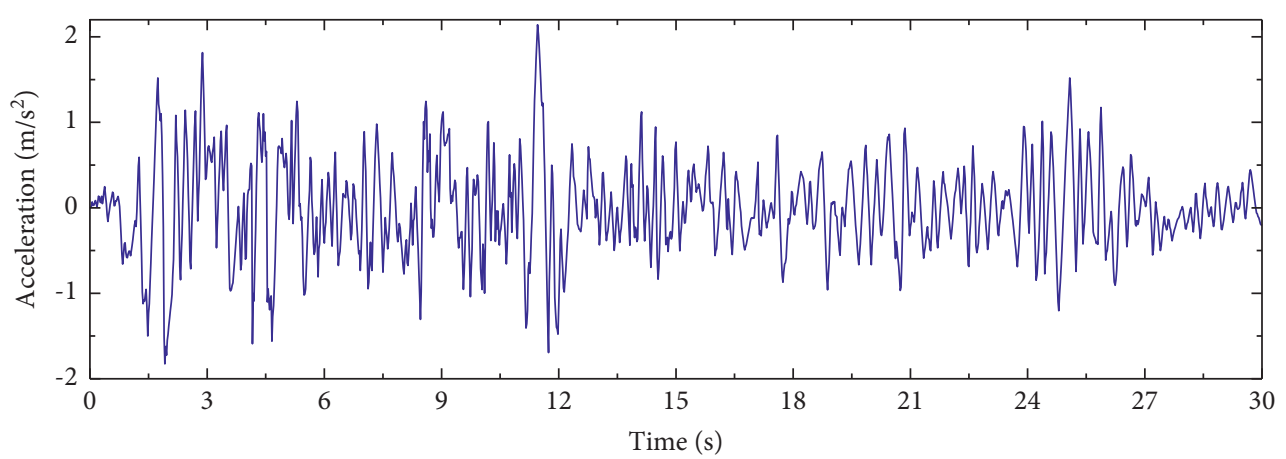

Figure 27: The East-West direction of EI Centro seismic load curve.

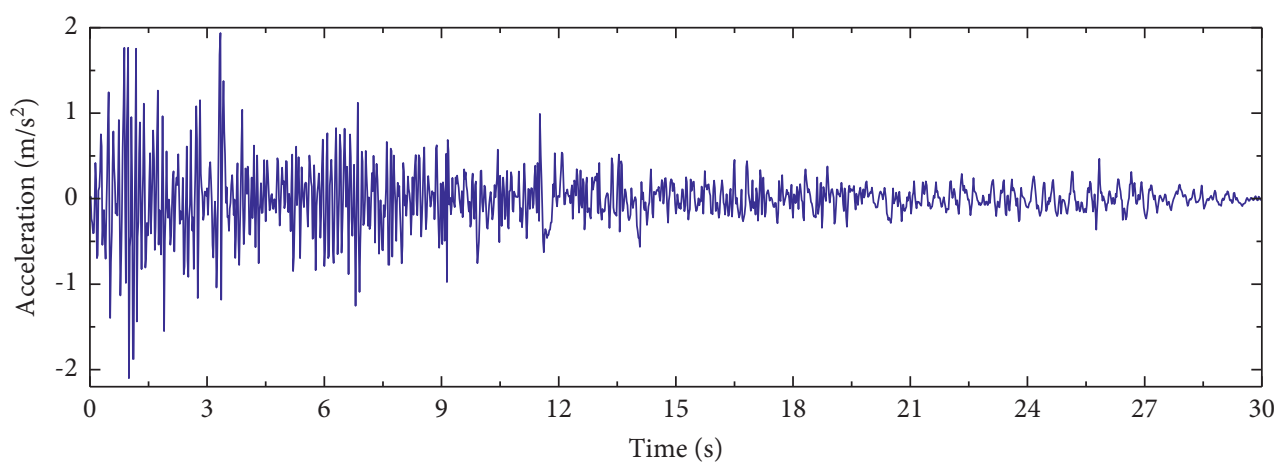

Figure 28: The Up-Down direction of EI Centro seismic load curve.

longer than the Bathe method and the Generalized- $\alpha$ method with the same time step $\Delta t=0.024 \mathrm{~s}$, while the Bathe method $(\Delta t=0.016 \mathrm{~s})$ and the Generalized- $\alpha$ method $(\Delta t=0.008 \mathrm{~s})$ have longer elapsed time than the Wen method $(\Delta t=0.024 \mathrm{~s})$ and the OTTBIF method $(\Delta t=0.024 \mathrm{~s})$.

Different from the linear seismic response analysis, in each time step, the nonlinear seismic response analysis entails a large amount of computation time for the nonlinear hysteretic force. The composite time integration method adopts the linear interpolation scheme to calculate the hysteretic force required for each substep, which reduces time cost for nonlinear problems. Therefore, the composite method can greatly reduce time cost for nonlinear hysteretic force calculation.

This example verifies effectiveness of the Wen method and other composite time integration methods for structural nonlinear seismic response analysis. The three-step Wen method and the OTTBIF method have higher efficiency than the Generalized- $\alpha$ and Bathe methods.

4.3.2. A Space Truss. As shown in Figure 26, a space truss is considered. The total height of the structural system is $84 \mathrm{~m}$, including $8 \mathrm{~m}$ for the first story and $76 \mathrm{~m}$ for the next 19 stories. The horizontal size of the structure in the first five stories is $30 \times 40 \mathrm{~m}$, which is divided into $5 \times 3$ grids; the horizontal size of the next 5 stories is $20 \times 24$ meters, which is divided into $3 \times 2$ grids; and the horizontal size of 11 to 20 stories is $20 \times 16$ meters, which is divided into $2 \times 2$ grids. The total degree of freedom of the structural system is 810 . The elastic modulus of all linear elements is $2.1 \times 10^{11} \mathrm{~N} / \mathrm{m}^{2}$. The mass of all elements is $7850 \mathrm{~kg} / \mathrm{m}^{2}$, and the cross-sectional area is $25 \mathrm{~cm}^{2}$. All elements are connected by rigid nodes. The 16 cross braces (marked in blue) in the first story are nonlinear elements. The Bouc-Wen hysteresis model [28] is adopted for these elements, and the expression of motion equation is given by equations (21)-(23). The nonlinear parameters $k_{\text {pre }}$ and $k_{\text {post }}$ of the 6 cross braces (perpendicular to the $y$-axis) are, respectively, $29.8 \mathrm{MN} / \mathrm{m}$ and $14.9 \mathrm{MN} / \mathrm{m}$ [32]. To obtain strong nonlinearity, the critical point of yield $Q_{y}$ is adopted as $4770 \mathrm{~N}$ which is far less than that in [32]. Likewise, the nonlinear parameters $k_{\text {pre }}$ and $k_{\text {post }}$ of the 10 cross braces (perpendicular to the $x$-axis) are, respectively, $27.3 \mathrm{MN} / \mathrm{m}$ and $13.65 \mathrm{MN} / \mathrm{m}$ [32], while a small critical point of yield $Q_{y}=3860 \mathrm{~N}$ is adopted to obtain strong nonlinearity. This structure system is also used in [32]; however, in this analysis, bar element is used and different parameters are selected.

The system is subjected to East-West (shown in Figure 27), North-South (shown in Figure 19), and Up-Down (shown in Figure 28) directions of 1940 EI Centro seismic loads in the $X$-axis, $Y$-axis, and $Z$-axis, respectively. The dynamic analysis in point A (seen in Figure 26) is considered. The calculated hysteretic restoring force curves of the 16 nonlinear elements are shown in Figure 29 where the internal force of all nonlinear elements exceeds yield limit. The displacement and velocity results (in time duration 

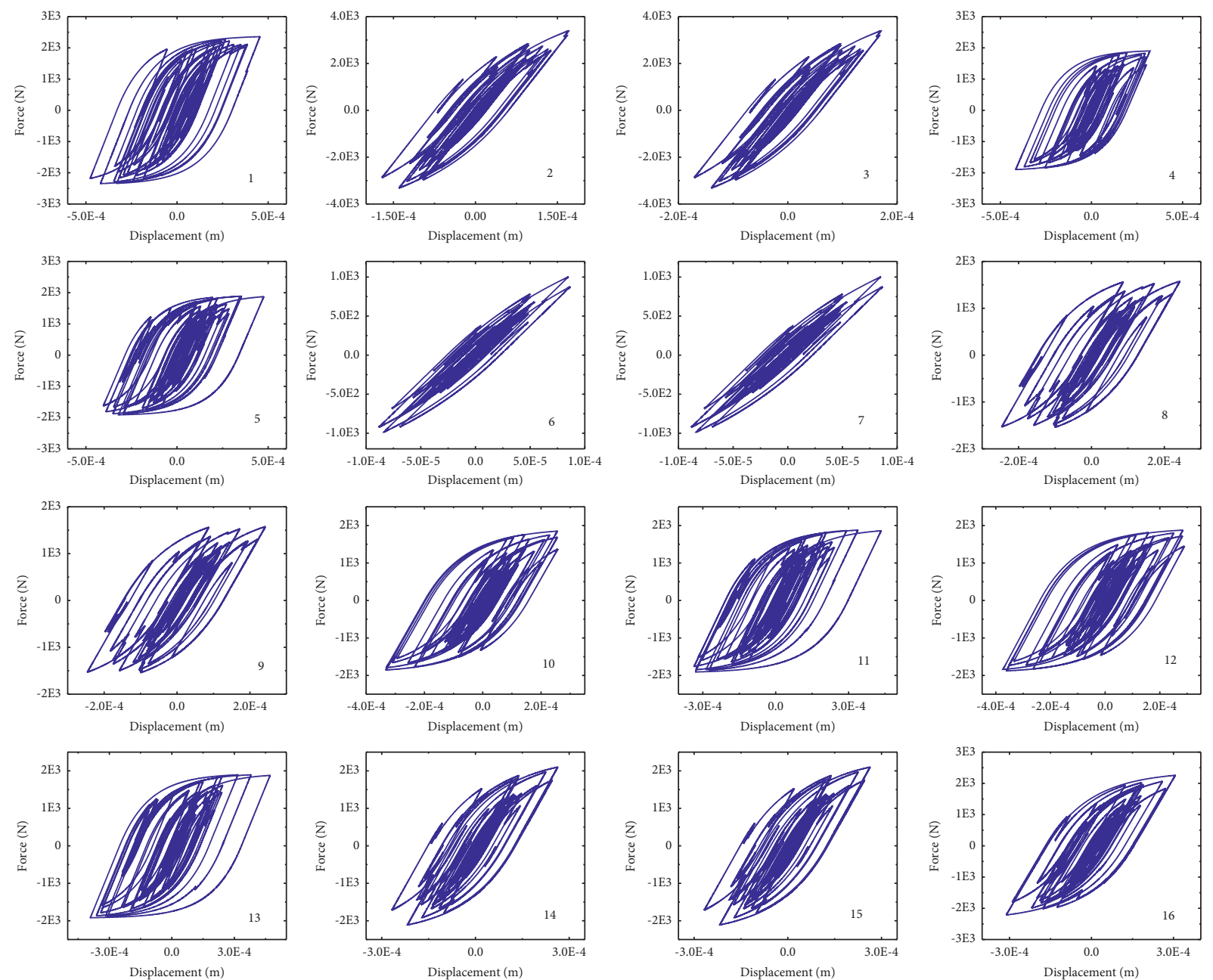

FIgURE 29: The hysteretic force of all 16 nonlinear elements.

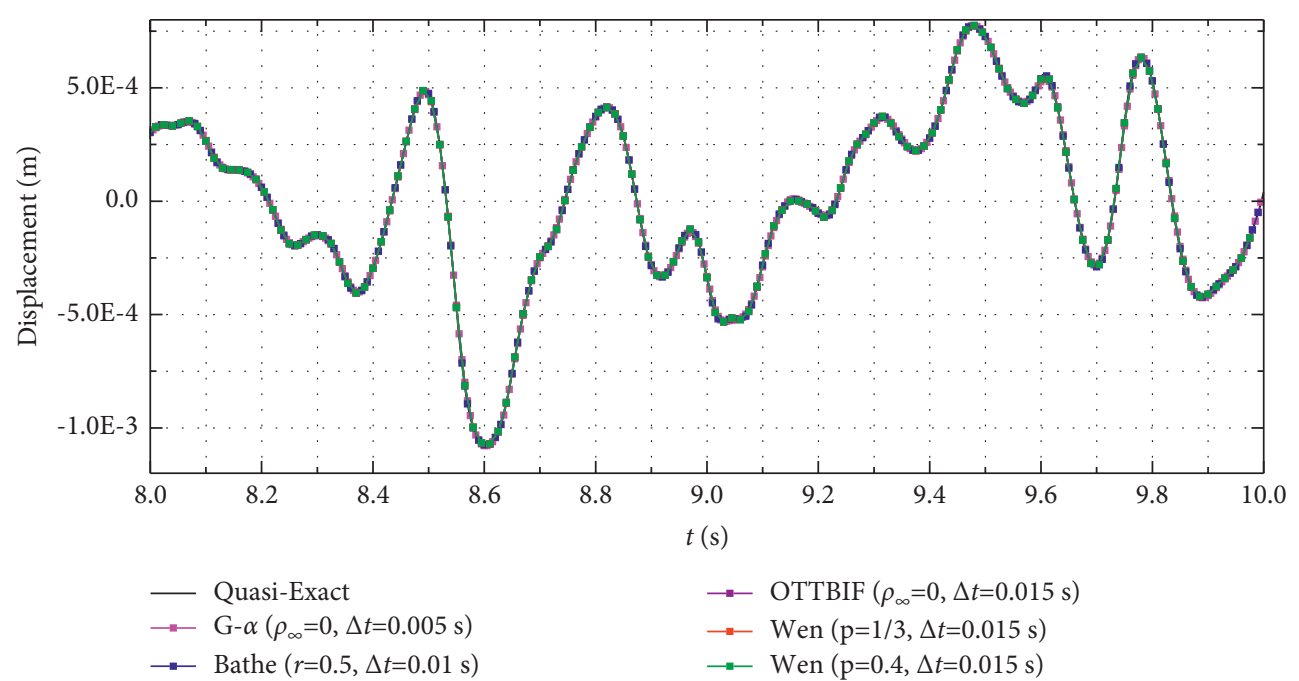

(a)

FIgure 30: Continued. 


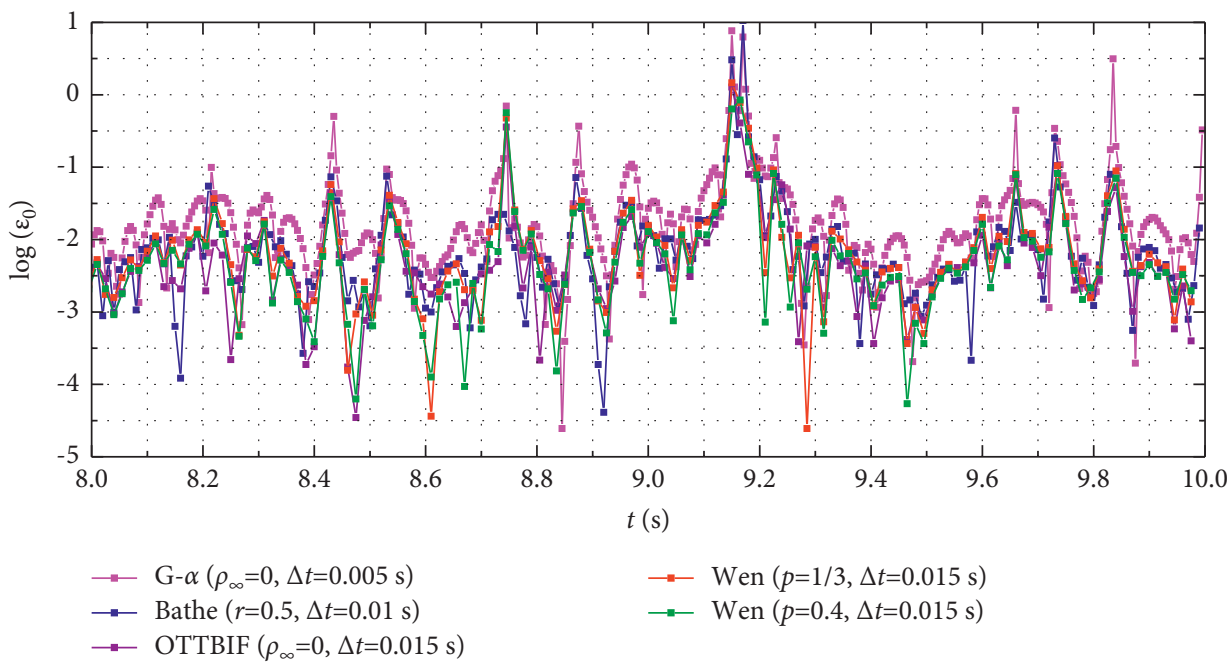

(b)

Figure 30: The displacement results of point A and its relative error from various methods. (a) Displacement results of 8-10 s. (b) The relative error results of displacement of 8-10s.

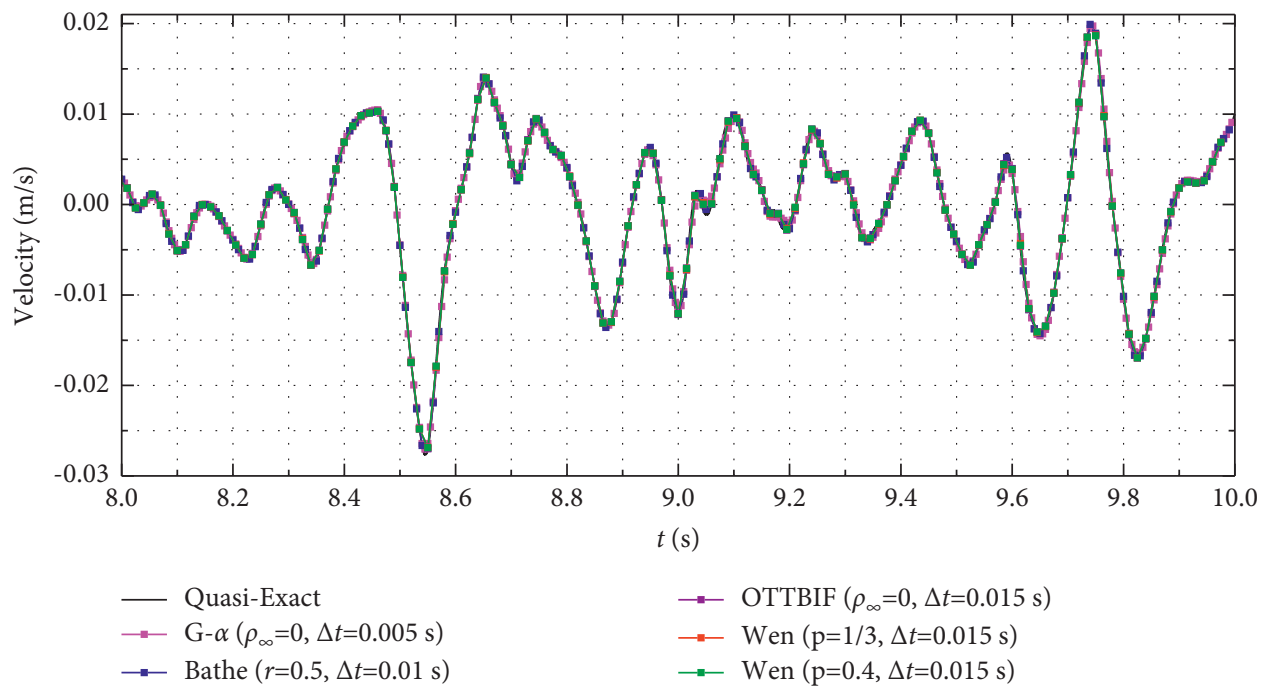

(a)

Figure 31: Continued. 


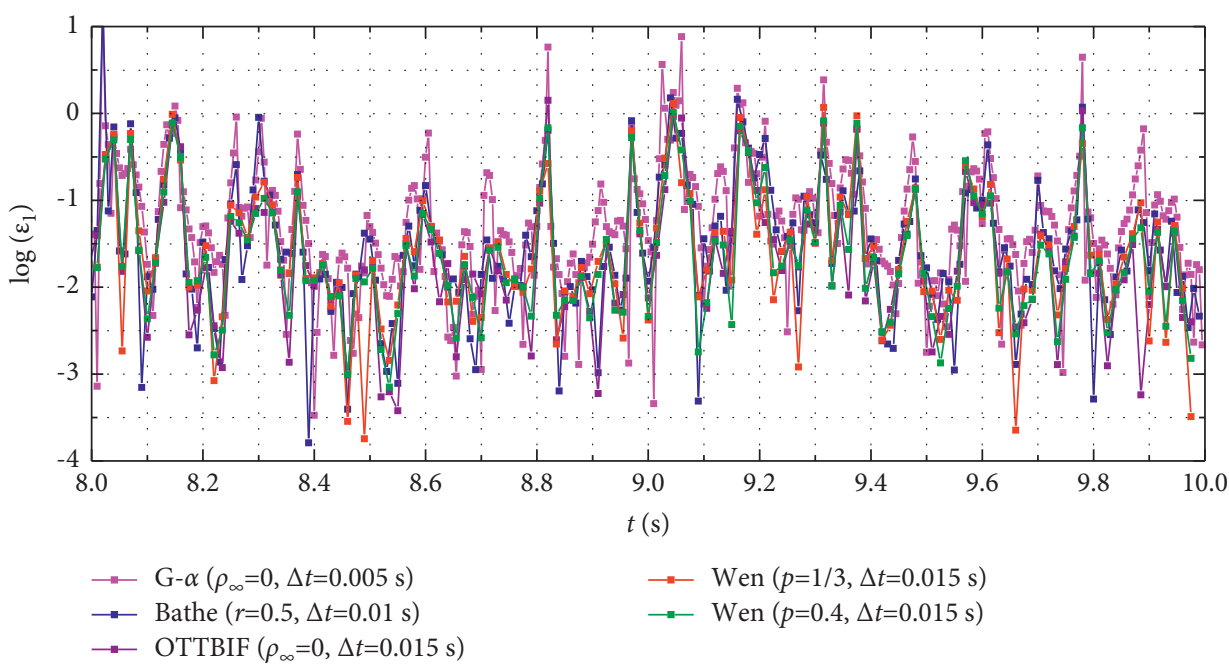

(b)

Figure 31: The velocity results of point A and the relative errors from various methods. (a) Velocity results of 8-10 s. (b) The relative error results of velocity of $8-10 \mathrm{~s}$.

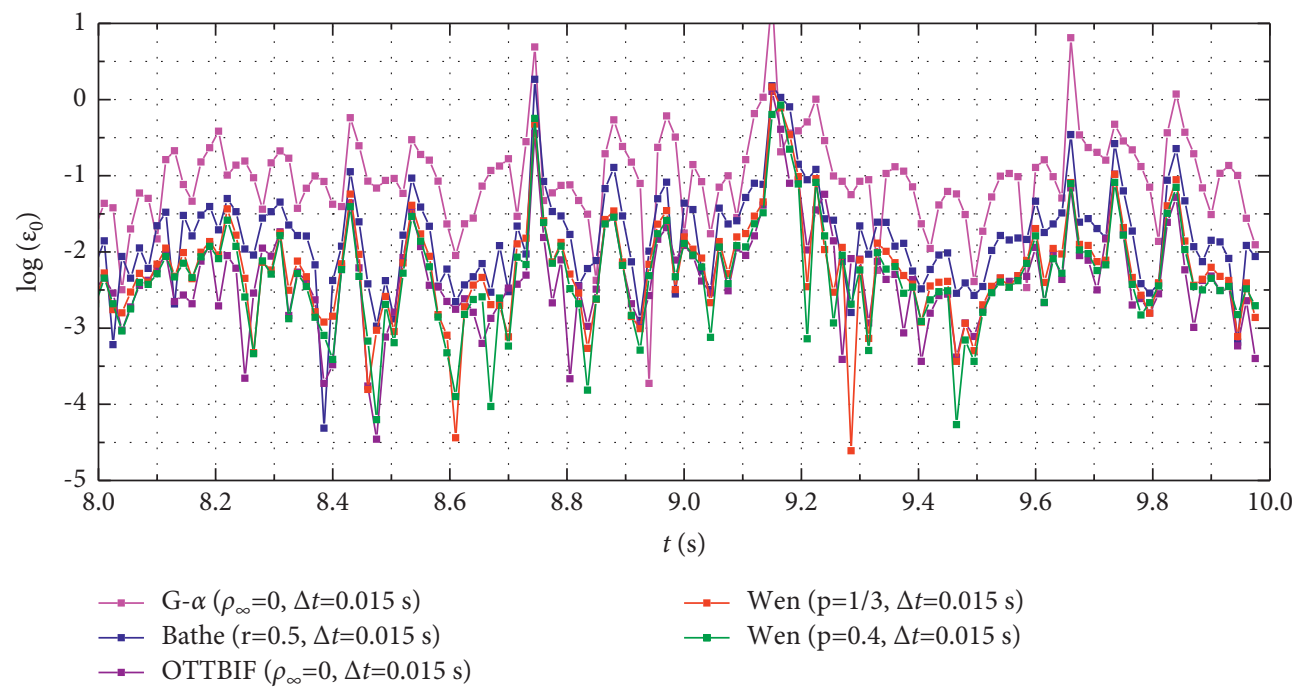

FIgURE 32: The displacement errors of various methods with the same time step $\Delta t=0.015 \mathrm{~s}$.

8-10 s) of point A using different $\Delta t$ for various methods are, respectively, plotted in Figures 30 and 31. The displacement and velocity errors of different methods with the same time step $\Delta t=0.015 \mathrm{~s}$ are, respectively, plotted in Figures 32 and 33. Time cost of various methods with different time steps in time history of $0-30$ s is listed in Table 4 .

Figures 30 and 31 illustrate that four methods using different time steps have acceptable accuracy. However, the Generalized- $\alpha$ method has the largest errors. The Bathe method shows slightly larger error than that of the Wen method and OTTBIF method. The Wen method has close calculation accuracy as the OTTBIF method. Time cost of four methods follows Generalized- $\alpha(\Delta t=0.005)>$ Bathe $(\Delta t=0.01)>$ OTTBIF $\quad(\Delta t=0.015)>$ Wen $\quad(\Delta t=0.015)$. Therefore, computation efficiency of four methods follows Wen $>$ OTTBIF $>$ Bathe $>$ Generalized $-\alpha$. As for the same time step (see Figures 32 and 33), the OTTBIF method and the Wen method show much higher accuracy than the Bathe method and Generalized- $\alpha$ method. This example verifies effectiveness of the Wen method and other composite time integration methods for nonlinear seismic response analysis of space truss. 


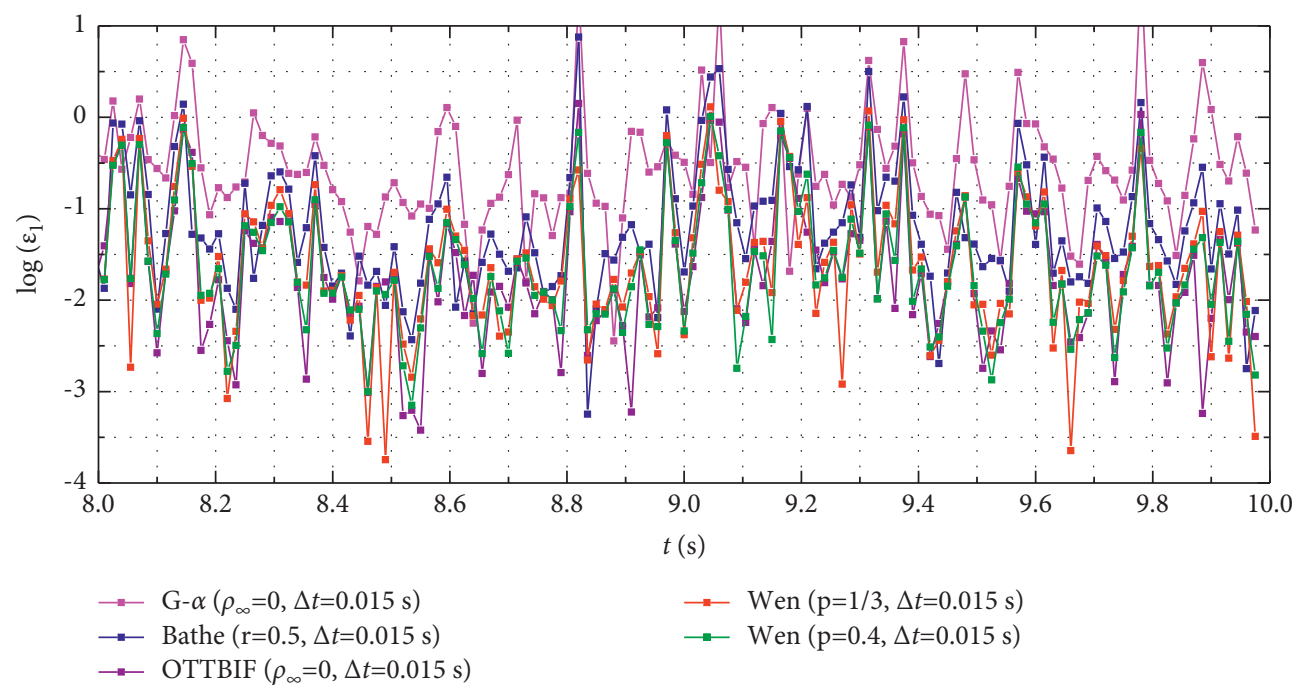

FIgUre 33: The velocity errors of various methods with the same time step $\Delta t=0.015 \mathrm{~s}$.

TABLE 4: Time cost of various methods in time history of $0-30$ s, for example 4.3.2.

\begin{tabular}{|c|c|c|c|c|c|c|c|}
\hline Method & $\mathrm{G}-\alpha\left(\rho_{\infty}=0\right)$ & $\mathrm{G}-\alpha\left(\rho_{\infty}=0\right)$ & Bathe $(r=0.5)$ & Bathe $(r=0.5)$ & OTTBIF $\left(\rho_{\infty}=0\right)$ & Wen $(p=1 / 3)$ & Wen $(p=0.4)$ \\
\hline Time Step (s) & 0.005 & 0.015 & 0.01 & 0.015 & 0.015 & 0.015 & 0.015 \\
\hline Elapsed time (s) & 180.1 & 58.4 & 91.0 & 58.9 & 88.4 & 85.1 & 85.1 \\
\hline
\end{tabular}

\section{Conclusions}

In this work, the Wen method is applied to the analysis of nonlinear dynamics. The calculation procedure of the Wen method for nonlinear analysis is proposed. The basic properties of the Wen method are provided. Numerical simulations of some nonlinear dynamic problems, especially for nonlinear seismic response analysis, are studied by the Wen method and other competitive methods. The conclusion of this study can be summarized as follows.

(1) The Wen method shows concise calculation procedure for nonlinear dynamics analysis.

(2) It is observed that, for the Wen method, the parameter $p$ values of desirable algorithmic properties (including $\mathrm{AD}, \mathrm{PE}$, and analytical accuracy) for linear dynamics are also suggested for nonlinear dynamic analysis.

(3) Numerical solutions of three nonlinear systems illustrate that the Wen method (the $p=0.4$ case) achieves desirable accuracy and efficiency for nonlinear dynamic examples and structural nonlinear seismic response analysis.

(4) In general, the theoretical analysis and numerical simulation demonstrate that the Wen method is a desirable candidate for nonlinear dynamic problems.

\section{Data Availability}

The raw/processed data can be obtained by contacting the corresponding author by e-mail (De Zhou 210026@ csu.edu.cn).

\section{Conflicts of Interest}

The authors declare that they have no conflicts of interest.

\section{Acknowledgments}

This research was substantially supported by the National Natural Science Foundation of China (no.12072375).

\section{References}

[1] G. Liu, S. Fomel, and X. Chen, "Time-frequency analysis of seismic data using local attributes," Geophysics, vol. 76, no. 6, p. 23P, 2011.

[2] L. Li, Y. Hu, and X. Wang, "Harmonic response calculation of viscoelastic structures using classical normal modes an iterative method," Computers \& Structures, vol. 133, pp. 39-50, 2014.

[3] M. A. Dokainish and K. Subbaraj, "A survey of direct timeintegration methods in computational structural dynamics-I. Explicit methods," Computers \& Structures, vol. 32, no. 6, pp. 1371-1386, 1989.

[4] D. Soares, "A novel family of explicit time marching techniques for structural dynamics and wave propagation models," Computer Methods in Applied Mechanics and Engineering, vol. 311, no. .1, pp. 838-855, 2016.

[5] W. Wen, H. Lei, K. Wei, B. Xu, S. Duan, and D. Fang, "An improved time integration scheme based on uniform cubic B-splines and its application in structural dynamics," Applied Mathematics and Mechanics, vol. 38, no. 6, pp. 889-908, 2017.

[6] C. Hoff and P. J. Pahl, "Development of an implicit method with numerical dissipation from a generalized single-step algorithm for structural dynamics," Computer Methods in 
Applied Mechanics and Engineering, vol. 67, no. 3, pp. 367385, 1988.

[7] W. Kim and S. Y. Choi, "An improved implicit time integration algorithm the generalized composite time integration algorithm," Computers \& Structures, vol. 196, pp. 341-354, 2018.

[8] K. J. Bathe, Finite Element Procedures, Prentice-Hall, Upper Saddle River, USA, 1996.

[9] N. M. Newmark, "A method of computation for structural dynamics," Journal of the Engineering Mechanics Division, vol. 85, no. 3, pp. 67-94, 1959.

[10] H. M. Hilber, T. J. R. Hughes, and R. L. Taylor, "Improved numerical dissipation for time integration algorithms in structural dynamics," Earthquake Engineering \& Structural Dynamics, vol. 5, no. 3, pp. 283-292, 1977.

[11] J. Chung and G. M. Hulbert, "A time integration algorithm for structural dynamics with improved numerical dissipation the generalized- $\alpha$ method," Journal of Applied Mechanics, vol. 60, no. 2, pp. 371-375, 1993.

[12] T. Hughes, "Analysis of transient algorithms with particular reference to stability behavior," Computer Methods for Transient Analysis, vol. 1, pp. 67-155, 1983.

[13] K. J. Bathe and E. L. Wilson, "NONSAP-A general finite element program for nonlinear dynamic analysis of complex structures," Division of Structural Engineering and Structural Mechanics, vol. M-3-1, pp. 1-13, 1973.

[14] D. Kuhl and M. A. Crisfield, "Energy-conserving and decaying algorithms in non-linear structural dynamics," International Journal for Numerical Methods in Engineering, vol. 45, no. 5, pp. 569-599, 1999.

[15] F. Armero and I. Romero, "On the formulation of highfrequency dissipative time-stepping algorithms for nonlinear dynamics. Part II second-order methods," Computer Methods in Applied Mechanics and Engineering, vol. 190, no. 51-52, pp. 6783-6824, 2001.

[16] K. J. Bathe and M. M. I. Baig, "On a composite implicit time integration procedure for nonlinear dynamics," Computers \& Structures, vol. 83, no. 31, pp. 2513-2524, 2005.

[17] K. J. Bathe, "Conserving energy and momentum in nonlinear dynamics a simple implicit time integration scheme," Computers \& Structures, vol. 85, no. 7, pp. 437-445, 2007.

[18] G. Noh, S. Ham, and K.-J. Bathe, "Performance of an implicit time integration scheme in the analysis of wave propagations," Computers \& Structures, vol. 123, pp. 93-105, 2013.

[19] S. Dong, "BDF-like methods for nonlinear dynamic analysis," Journal of Computational Physics, vol. 229, no. 8, pp. 3019$3045,2010$.

[20] Y. Chandra, Y. Zhou, I. Stanciulescu, T. Eason, and S. Spottswood, "A robust composite time integration scheme for snap-through problems," Computational Mechanics, vol. 55, no. 5, pp. 1041-1056, 2015.

[21] W. B. Wen, K. Wei, H. S. Lei, S. Y. Duan, and D. N. Fang, "A novel sub-step composite implicit time integration scheme for structural dynamics," Computers \& Structures, vol. 182, pp. 176-186, 2017.

[22] H. M. Zhang and Y. F. Xing, "Optimization of a class of composite method for structural dynamics," Computers \& Structures, vol. 202, pp. 60-73, 2018.

[23] Y. Xing, Y. Ji, and H. Zhang, "On the construction of a type of composite time integration methods," Computers \& Structures, vol. 221, no. 4, pp. 157-178, 2019.

[24] Y. Ji and Y. Xing, "An optimized three-sub-step composite time integration method with controllable numerical dissipation," Computers \& Structures, vol. 231, no. 2, Article ID 106210, 2020.

[25] T. Liu, F. Huang, W. Wen, X. He, S. Duan, and D. Fang, "Further insights of a composite implicit time integration scheme and its performance on linear seismic response analysis," Engineering Structures, vol. 241, Article ID 112490, 2021.

[26] W. Wen, S. Deng, N. Wang, S. Duan, and D. Fang, "An improved sub-step time-marching procedure for linear and nonlinear dynamics with high-order accuracy and high-efficient energy conservation," Applied Mathematical Modelling, vol. 90, no. 44, pp. 78-100, 2021.

[27] G. Noh and K.-J. Bathe, "An explicit time integration scheme for the analysis of wave propagations," Computers \& Structures, vol. 129, pp. 178-193, 2013.

[28] Y.-K. Wen, "Method for random vibration of hysteretic systems," Journal of the Engineering Mechanics Division, vol. 102, no. 2, pp. 249-263, 1976.

[29] Gaurav, S. F. Wojtkiewicz, and E. A. Johnson, "Efficient uncertainty quantification of dynamical systems with local nonlinearities and uncertainties," Probabilistic Engineering Mechanics, vol. 26, no. 4, pp. 561-569, 2011.

[30] G. Augusti, "Dynamics of structures Theory and applications to earthquake engineering," Engineering Structures, vol. 17, no. 6, p. 968, 1995.

[31] W. Gautschi, Numerical Analysis, Springer Science \& Business Media, Berlin, Germany, 1997.

[32] V. Yaghoubi, T. Abrahamsson, and E. A. Johnson, "An efficient exponential predictor-corrector time integration method for structures with local nonlinearity," Engineering Structures, vol. 128, pp. 344-361, 2016. 